University of South Florida

DIGITAL COMMONS

@ UNIVERSITY OF SOUTH FLORIDA
Digital Commons @ University of

South Florida

$12-1-2003$

\title{
Senior Transportation Alternatives: Why Are They Important and What Makes Them Work?
}

CUTR

Follow this and additional works at: https://digitalcommons.usf.edu/cutr_nctr

\section{Scholar Commons Citation}

CUTR, "Senior Transportation Alternatives: Why Are They Important and What Makes Them Work?" (2003). Research Reports. 236.

https://digitalcommons.usf.edu/cutr_nctr/236

This Technical Report is brought to you for free and open access by the National Center for Transit Research (NCTR) Archive (2000-2020) at Digital Commons @ University of South Florida. It has been accepted for inclusion in Research Reports by an authorized administrator of Digital Commons @ University of South Florida. For more information, please contact digitalcommons@usf.edu. 


\section{Senior Transportation Alternatives: Why Are They Important and What Makes Them Work?}
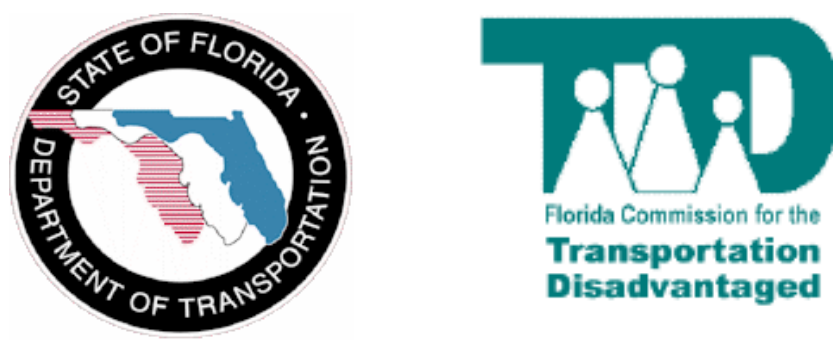

State of Florida Department of Transportation Florida Commission for the Transportation Disadvantaged 605 Suwannee Street, MS-49

Tallahassee, FL 32399-0450

(850) 410-5700

Project Manager:

Karen Somerset, Program Accountability Manager

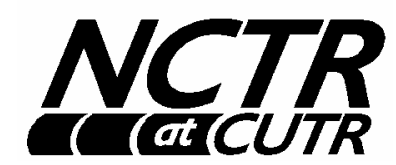

National Center for Transit Research

Center for Urban Transportation Research

University of South Florida

4202 E. Fowler Avenue, CUT100

Tampa, FL 33620-5375

(813) 974-3120

http://www.nctr.usf.edu/

Principal Investigator: Chandra C. Foreman, Research Associate

Project Staff:

Lisa E. Tucker, Research Associate

Jennifer Flynn, Graduate Research Assistant

Michael West, Graduate Research Assistant

The opinions, findings, and conclusions expressed in this publication are those of the authors and not necessarily those of the U.S. Department of Transportation or the State of Florida Department of Transportation. 


\begin{tabular}{|c|c|}
\hline $\begin{array}{l}\text { 1. Report No. } \\
\text { NCTR - } 473 \text { - } 09\end{array}$ & 3. Recipient's Catalog No. \\
\hline \multirow{2}{*}{$\begin{array}{l}\text { 4. Title and Subtitle } \\
\text { Senior Transportation Alternatives: Why Are They Important } \\
\text { and What Makes Them Work? }\end{array}$} & $\begin{array}{l}\text { 5. Report Date } \\
\text { December } 2003\end{array}$ \\
\hline & 6. Performing Organization Code \\
\hline $\begin{array}{l}\text { 7. Author(s) } \\
\text { Foreman, Chandra C.; Tucker, Lisa E.; Flynn, Jennifer; and } \\
\text { West. Michael }\end{array}$ & 8. Performing Organization Report No. \\
\hline \multirow{2}{*}{$\begin{array}{l}\text { 9. Performing Organization Name and Address } \\
\text { National Center For Transit Research (NCTR) } \\
\text { University of South Florida CUT } 100 \\
4202 \text { East Fowler Avenue, Tampa, FL } 33620\end{array}$} & 10. Work Unit No. \\
\hline & $\begin{array}{l}\text { 11. Contract or Grant No. } \\
\text { DTRS98-G-0032 }\end{array}$ \\
\hline \multirow[t]{2}{*}{$\begin{array}{l}\text { 12. Sponsoring Agency Name and Address } \\
\text { Office of Research and Special Programs (RSPA) } \\
\text { U.S. Department of Transportation, Washington, D.C. } 20590\end{array}$} & 13. Type of Report and Period Covered \\
\hline & 14. Sponsoring Agency Code \\
\hline
\end{tabular}

Supported by a grant from the State of Florida Department of Transportation and the Florida Commission for the Transportation Disadvantaged

16. Abstract

As baby boomers move into retirement age, the United States is realizing a growing number of automobile drivers over the age of 65. In response to this phenomenon, many communities are implementing or are considering implementing various strategies to improve transportation alternatives for seniors who want to reduce or eliminate driving. This report is written for a wide audience, including municipalities, senior transportation providers and new starts, transit agencies, senior centers, senior support programs, or any other person or agency interested in improving transportation options for seniors. It is presented in five chapters. Chapter One includes a literature review of previous studies related to senior transportation issues. Chapter Two provides a summary of the results of four focus groups that were held with seniors in various cities in Florida. Chapter Three presents the results of a written survey that was sent to senior transportation providers throughout the country. Chapter Four identifies some of the successful practices and strategies of the participants in the senior transportation provider survey. Finally, Chapter Five presents a summary and recommendations.

17. Key Words

Senior citizens; elderly; transportation alternatives; volunteers; senior service providers Information Service (NTIS), 5285 Port Royal Road, Springfield, VA 22161, (703) 487-4650, http://www.ntis.gov/, and through the NCTR web site at http://www.nctr.usf.edu/.

20. Security Classif. (of this page)

Unclassified
21. No. of pages

102
22. Price 


\section{Table of Contents}

INTRODUCTION

\section{CHAPTER ONE}

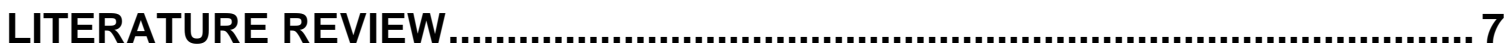

SENIOR DRIVER StATISTICS, ChaRACTERISTICS, AND BEHAVIOR ......................... 8

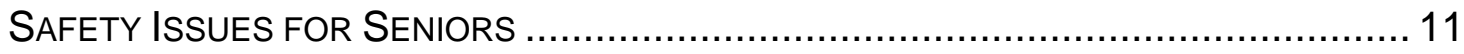

SENIOR DRIVER ASSESSMENTS, EVALUATIONS, AND LICENSING .......................... 13

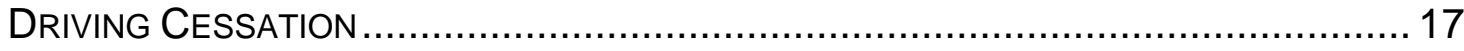

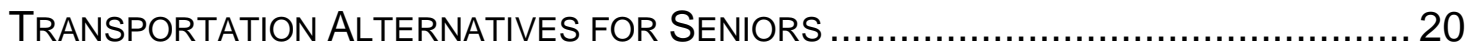

\section{CHAPTER TWO}

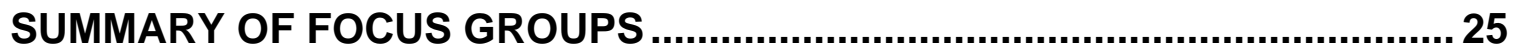

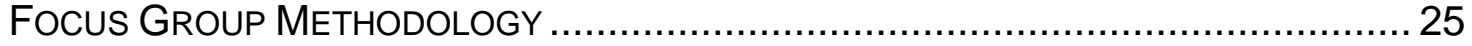

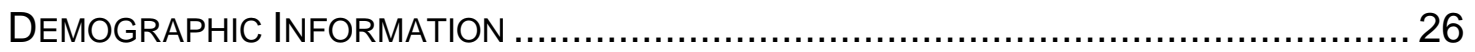

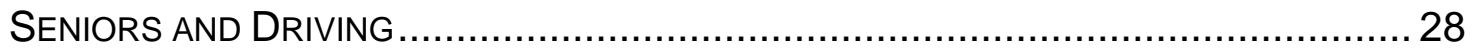

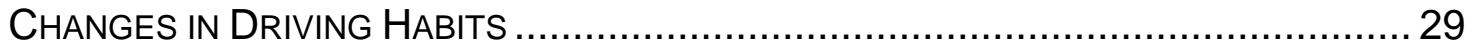

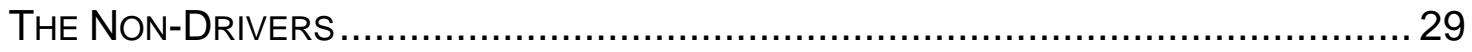

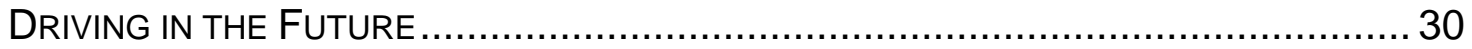

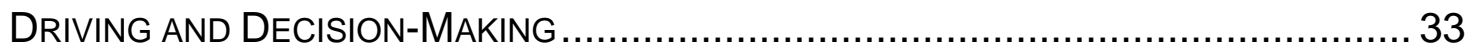

\section{CHAPTER THREE}

SURVEY OF SENIOR TRANSPORTATION PROVIDERS.............................. 35

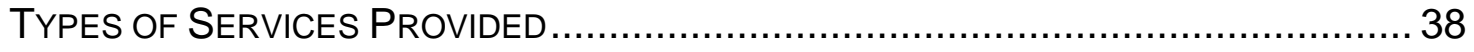

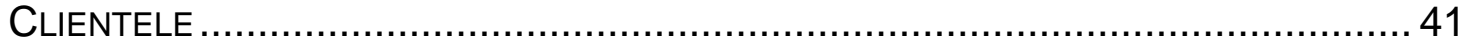

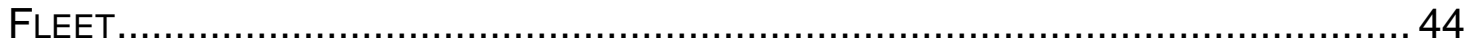

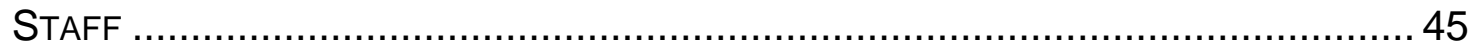

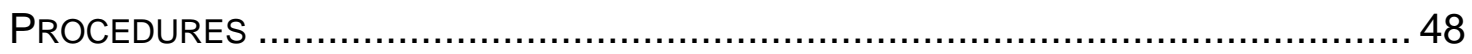

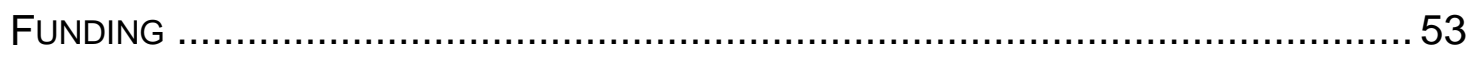

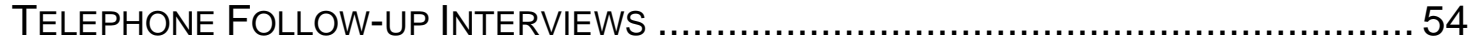

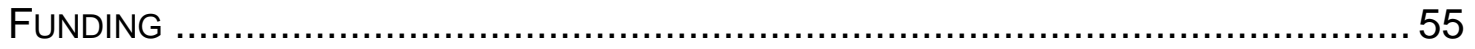

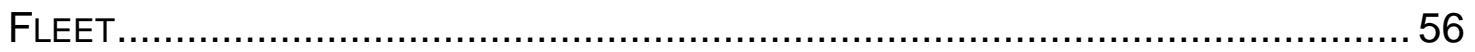

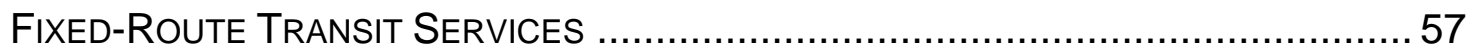

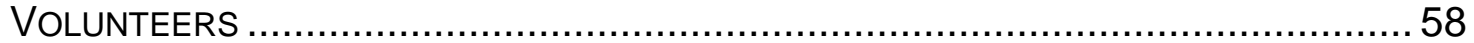

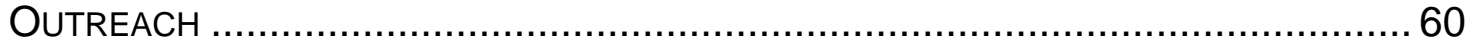

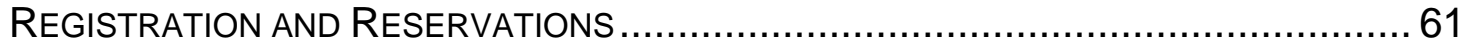

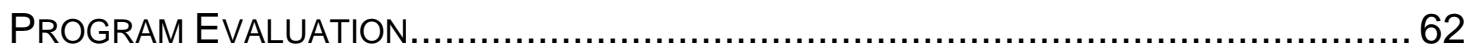

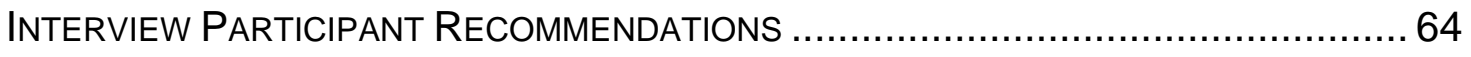

\section{CHAPTER FOUR}

SUCCESSFUL STRATEGIES IN SENIOR TRANSPORTATION SERVICES... 67

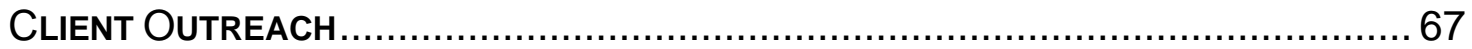

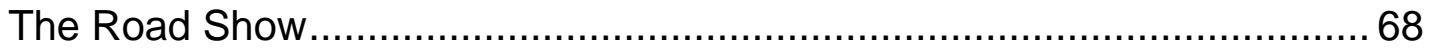

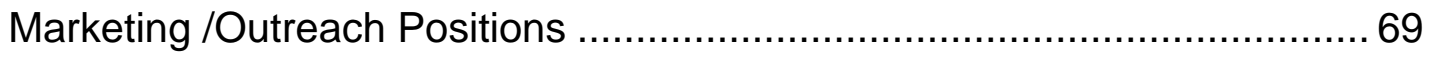




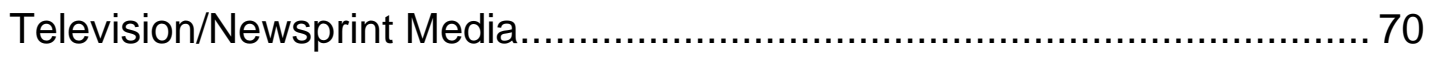

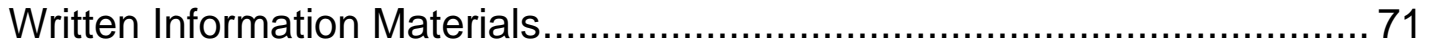

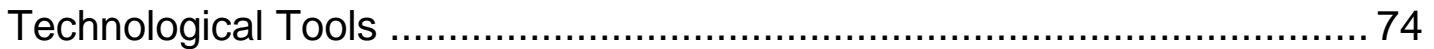

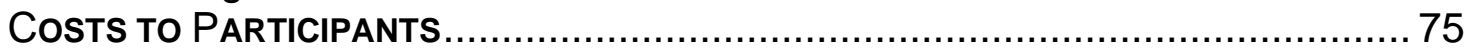

Community Roads Scholarship Program............................................... 76

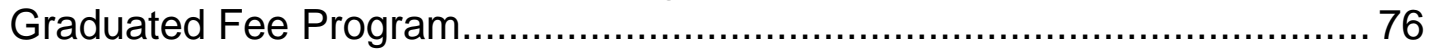

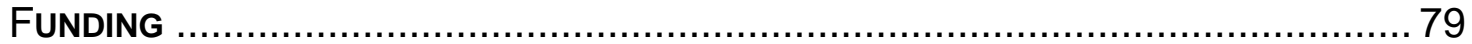

Receives Financial Support from Government Sources ............................ 79

Receives No Financial Support from Government Sources ...................... 80

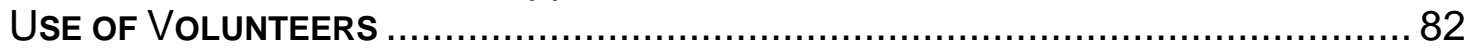

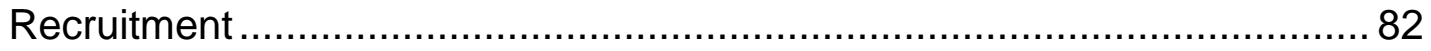

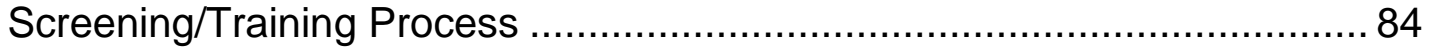

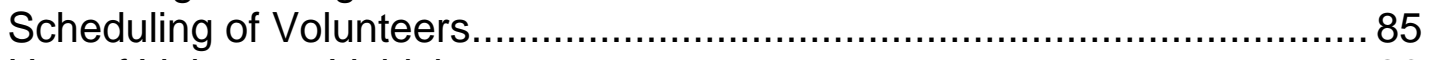

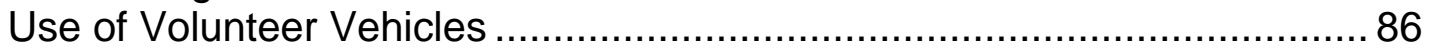

CHAPTER FIVE

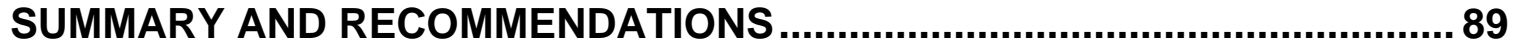

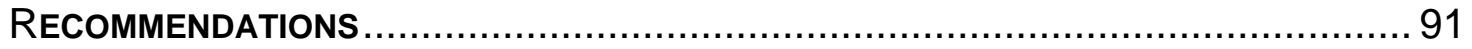

AFTERWORD

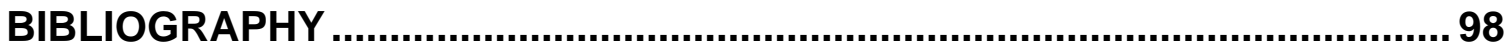




\section{Introduction}

As baby boomers move into retirement age, the United States is realizing a growing number of automobile drivers over the age of 65 . In response to this phenomenon, many communities are implementing or are considering implementing various strategies to improve transportation alternatives for seniors who want to reduce or eliminate driving.

Initially, the National Center for Transit Research (NCTR) at the Center for Urban Transportation Research (CUTR) proposed to identify best practices in voluntary driving cessation programs for seniors in the country. Immediately, there appeared to be a void in documentation regarding such programs. Further review and investigation suggested that programs labeled 'voluntary driver cessation programs" are not common. While there are a few mandated driver cessation strategies adopted by states around the country, mainly in the form of drivers license revocation as a result of failing driving or vision tests, the majority of programs related to senior drivers are best described as alternative transportation programs.

In response to the lack of information regarding programs that are marketed as voluntary driver cessation programs for seniors, NCTR modified the scope of its project to include identifying senior transportation programs throughout the country that are dedicated to addressing the needs and concerns of seniors, as depicted in both the literature and focus groups conducted by NCTR.

This report is written for a wide audience, including municipalities, senior transportation providers and new starts, transit agencies, senior centers, senior support programs, or any other person or agency interested in improving transportation options for seniors. It is presented in five chapters. Chapter One includes a literature review of previous studies related to senior transportation issues. Chapter Two provides a summary of the results of four focus groups that were held with seniors in various cities in Florida. Chapter Three presents the results of a written survey that was sent to senior transportation providers throughout the country. Chapter Four identifies some of the successful practices and strategies of the participants in the senior transportation provider survey. Finally, Chapter Five presents a summary and recommendations. 
Page 6 


\section{Chapter One Literature Review}

Chapter One includes the results of a literature review of previous studies related to senior transportation issues. This chapter contains a review and summarization of relevant studies.

The literature review allowed NCTR researchers to become more affiliated with topics related to senior driving, but it also provided guidance in preparation for the senior focus group discussions. Researchers were interested in finding whether those issues which were thought to be of great importance to seniors, according to the literature review articles, were in fact of importance to seniors in Florida. The results of the focus group discussions are discussed in Chapter Two.

Extensive literature searches were conducted using the TRIS (Transportation Research Information Services) literature database made available from the Transportation Research Board and the resource library at the Center for Urban Transportation Research. Every attempt was made to obtain and review the most current literature available. All literature was reviewed for relevancy to the topic and summarized. The literature reviewed addressed a variety of issues facing seniors regarding their mobility and their decision to drive or discontinue driving. The results of this literature review have been synthesized into six major categories of senior transportation issues. Those categories are: senior driver characteristics; statistics and forecasting; safety issues; evaluations, assessments, and licensing; driving cessation and the effects of driving cessation or reduction on seniors; and transportation alternatives. While the total number of categories applicable to the issue of senior mobility can be multitudinous, some of the more significant and encompassing categories have been selected in this study to reflect the range of issues and to ensure that some of the more important issues are given due attention.

The categories, as identified above, are presented in the following order. The first section provides an overview of literature related to senior driver characteristics and behavior, as well as literature pertaining to senior driver statistics and how those statistics have changed over time. The second category

Senior Transportation Alternatives: Why Are They Important and What Makes Them Work? 
summarizes the literature pertaining to safety issues for senior drivers. The third category addresses issues related to senior driver assessments, evaluations, and licensing. The fourth literature review category reflects on the findings related to driving cessation and the effects of driving reduction or cessation on the senior population. The final category deals with transportation alternatives for seniors who no longer drive or have significantly reduced their amount of driving.

Senior Driver Statistics, Characteristics, and Behavior

In an effort to gain an understanding of the demographics associated with the senior population, NCTR researchers began the literature review with a search for articles detailing the profile of the U.S. older population in the past, present, and future. As expected, many of the articles cite similar statistics, suggesting that similar original sources were used. The most detailed statistics on the senior population in the U.S. come from the U.S. Census Bureau and the U.S. Administration on Aging. According to a brief produced by the U.S. Census Bureau and prepared by Hetzel and Smith (2001), 35.0 million people 65 years of age and older were counted in the 2000 Census. The brief describes the increase in this age cohort as 12 percent since the 1990 Census count, in which 31.2 million people 65 years of age or older were counted. Hetzel and Smith compare the percent change in the population 65 years and older to the percent change in the total population from 1990 to 2000. It suggests that the 65 years and older population grew more slowly than the total population, which increased by 13.2 percent between 1990 and 2000 . The brief provides a concise overview of analysis on the 2000 census data for the 65 years and older population. In addition to comparing overall changes of 65 years and older population between 1990 and 2000, Hetzel and Smith also illustrate the degree to which the changes occurred for particular cohorts of that age group. For instance, census data show that of the older population, those 85 years and older had the highest percentage increase from 1990 to 2000 (38.0 percent) and those 65-74 years old increased by less than 2.0 percent.

The brief also illustrates that women outnumbered men in the 65 years and older population in 2000. The West and South regions of the country had the most growth in both total population and older population. The South region includes 
Florida, which had the highest proportion of population 65 years and older (17.6 percent) in the nation.

The Profile of Older Americans: 2002 is a brief put out annually by the U.S. Administration on Aging. While the data are taken directly from the 2000 U.S. Census, the presentation goes beyond the scope of the Hetzel and Smith brief to address future growth. According to the brief, by the year 2030, the older population (ages 65 and older) will more than double to 70.0 million. The biggest age cohort (85 years and older) will increase from 4.2 million in 2000 to 8.9 million by 2030 .

Other studies specifically address the driving behaviors of older Americans. According to Burkhardt (1998), senior women will drive in greater proportions and the number of drivers 85 years of age and older in 2030 will be at least four times greater than it was in 1998. In the article, which appeared in the SeptemberOctober 1998 issue of Community Transportation, Burkhardt states that between 1990 and 2020, the total annual mileage driven by male older drivers will increase by over 450 percent and by almost 500 percent for senior women drivers. The article further suggests that by 2030 , senior drivers will account for 18.9 percent of all vehicle miles driven, which is triple the 1990 figure. Dellinger, Langlois, and Li (2002) suggest that more than 40 million older Americans will be licensed by 2020 , while nearly 26 million are estimated to be licensed today.

Glasgow (2000) in an article in Rural America, states that the older population will double in size between 1995 and 2025. She further notes that driving is more common for men than women among drivers over the age of 65, and that driving is nearly universal among male and female baby boomers. According to Coughlin and Lacombe (1997) during the baby boom of the late 1940s and early 1950s, many people migrated out of the cities and into more rural areas. As a result, a considerable number of the older population does not live in areas where they are able to stop driving. Seventy-five percent of older Americans live in suburban areas where alternative forms of transportation are not readily available and the primary mode of transportation is the private vehicle.

Glasgow (2002) explains that the travel behaviors and patterns of older persons are functions of several factors, including environmental and personal constraints 
and preferences. She states that baby boomers will become seniors after having grown older in an automobile-dependent culture. Glasgow also notes that the number of older drivers is increasing because the population is aging and the rates of obtaining drivers' licenses have increased. She cites the reasons for increased licensing rates as changing preferences, different gender roles, and modified community structures.

In a paper related to senior mobility and safety in Michigan, Bruff and Evans (1999) note several trends. In Michigan, seniors make between 90 and 95 percent of their trips by private automobile. Seniors 65 years and older tend to travel during different time periods than the total population. Most make the majority of their trips between the morning and early afternoon commute periods (9 a.m.-3 p.m.). Bruff and Evans note that seniors in Michigan appear to make approximately the same percentage of trips as the total population during the afternoon peak period of 3 p.m.-6 p.m.

In 1997, the American Association for Retired Persons (AARP) published the results of a survey used to assess the habits, preferences, and attitudes that persons 75 years and older have regarding transportation (Straight 1997). The survey found the following of the respondents:

- Seventy-three percent of older persons drive;

- Older persons with higher incomes are much more likely to drive;

- Sixty-three percent of older drivers avoid driving at night;

- Fifty-one percent of older persons avoid driving during rush hour; and

- Thirty-three percent of older persons avoid certain routes.

In general, other literature related to the characteristics and travel behaviors of seniors offered similar findings. As the 2000 census data are becoming more readily available and have been more closely analyzed over the past few months, much of the literature of 2002 offers a very specific picture of the older population. 


\section{Safety Issues for Seniors}

Much of the literature regarding safety for senior drivers starts by citing statistics that show seniors account for a small percentage of traffic crash injuries and a more significant percentage of traffic crash fatalities. The National Center for Statistics and Analysis of the National Highway Traffic Safety Administration publishes an annual brief, Traffic Safety Facts 2001, which provides information on traffic safety and statistics. According to the brief, older persons 70 years and older accounted for 5 percent $(159,000)$ of all people injured in traffic crashes in 2001. This age group also accounted for 13 percent of all traffic fatalities. The fact sheet also notes that most traffic fatalities involving older drivers took place during the daytime (82 percent). A more detailed analysis of the statistics suggests that of the 4,808 senior drivers involved in fatal crashes in 2001, 31.8 percent were 70-74 years old, 31.1 percent were 75-79 years old, 22.3 percent were $80-84$ years old, and 14.9 percent were 85 years and older.

Safe Mobility in an Aging World, by Skinner and Stearns (1999) describes aging as "the slow, but cumulative, buildup of physical and cognitive deficits." Skinner and Stearns suggest that there is a strong relationship between aging and motor vehicle operation. Failing health and fragility are generally products of aging and appear to be the main causes of elevated risk to older drivers. As the baby boomer generation ages, according to Skinner and Stearns (1999), and the number of seniors increase as expected, it is also expected that the number of injury and fatal crashes involving seniors will increase.

In a fact sheet, Older Drivers, the Public Policy Institute of the AARP notes that the aging process introduces the possibility that functions such as vision, hearing, sensation, and cognitive and motor abilities may become impaired (Straight and Jackson, 1999). Examples of impairments include a decline in peripheral vision and short-term memory loss. These can affect a driver's ability to process information when merging with traffic or changing lanes.

Improving Transportation for a Maturing Society, produced by the U.S. Department of Transportation (1997), describes the aging process and the onset of fragility that may occur as people age. The report states that changes in physical strength, as well as the prevalence of medical conditions such as 
dementia and osteoporosis can have a negative impact on an older person's ability to operate a motor vehicle. Specific age related deficits identified in the report include the following:

- Reduced visual acuity at far distances

- Increased likelihood of having cataracts and/or glaucoma, especially after age 85

- Increased sensitivity to glare

- Less able to differentiate between tones

- Spatial orientation and visual-motor integration abilities diminish with age

- Reduced short-term memory

- Diminished searching and scanning abilities

- Slightly slower simple reaction time

- Reduced handgrip, shoulder, and back strength

- Posture less likely to be erect

- Elevated blood pressure

- More likely to have chronic respiratory problems

Skinner and Stearns (1999) suggest that some seniors are able to recognize physical and mental diminishments and adjust their driving behavior accordingly. Such adjustments may include less night driving, avoiding heavy traffic areas and high-speed roadways, driving with a navigator or passenger, and reduction in automobile usage. Deteriorating physical ability alone does not translate into higher crash rates, according to Skinner and Stearns (1999). It is generally the inability to acknowledge or recognize the deterioration and the absence of adjustments to driving behavior to counter the deterioration.

A University of Michigan report authored by Eby, Trombley, Molnar and Shope (1988), cites several studies on the potential of driver impairment due to medication use. Age-related health problems often increase the probability that older persons are taking medications. Many of these drugs, ranging from aspirin to psychotropic (mood-altering) medications, can affect one's ability to drive.

Bruff and Evans (1999) note that when State of Michigan crash characteristics were analyzed, they found that older persons are involved in more crashes at intersections with traffic controls. They also are involved in angle and left-turn 
traffic crashes more often. Crashes in either of these situations tend to result in more serious injuries or fatalities due to the point of impact (side) or the speed of impact.

\section{Senior Driver Assessments, Evaluations, and Licensing}

Many agree that most older drivers are able to identify the point at which their physical and mental abilities no longer allow them to operate a motor vehicle safely. However, there remains great concern that conditions exist in which some may remain behind the wheel well beyond what their physical abilities allow. Some believe that the answer to this concern is to subject older drivers to additional testing and evaluation in order to earn or maintain a license. This is an extremely controversial position that has received mixed response from seniors and organizations that represent their interests. The literature also addresses both sides of the issue. The literature suggests that public and private agencies throughout the country are conducting research to identify ways to improve driver assessment. State and federal transportation and health entities, as well as insurance agencies have an interest in developing and improving driver assessment methods. The controversy does not appear to be with the development and use of driver assessment tools, but how the results of those assessments are utilized. Some of the literature suggests that imposing driver assessments on seniors is unfair when they are used to revoke or refuse to renew an older person's license.

Based on the findings from the literature search, driver assessment programs fall into three categories: self-administering, community-based, and medical-based. The USAA Educational Foundation published a brochure with the AARP and the National Highway Traffic Safety Administration entitled, Driving Safely While Aging Gracefully (2002). The brochure includes an assessment that older drivers can administer on their own. The self-assessment is question-based and covers vision, physical fitness, and attention and reaction time. The assessment tool also offers users options for addressing deficiencies in these areas. Most of these options are related to improving their driving conditions, such as readjusting side mirrors, making left turns at intersections with protected signals, and limiting nighttime driving. 
The brochure also encourages readers to identify signs that it may be time to reduce or stop driving. It encourages the users to acknowledge if certain signs are present that may suggest it is time to consider cessation. Examples of such signs include family or friends of senior driver express concerns about his or her driving, driver sometimes gets lost while driving on once familiar routes, driver has been warned or ticketed by police for poor driving behavior, or a healthcare provider has advised the driver to restrict or stop driving. Finally, the brochure offers suggestions on what to do if the older driver has determined that he or she should reduce or stop driving. Self-assessment tools similar to the USAA brochure are made available through other agencies such as the American Automobile Association (AAA) and state and federal transportation entities.

Staplin et al. (1999) described the Gross Impairments Screening (GRIMPS) that was developed as a tool for early detection of driving impairments. GRIMPS is currently being utilized in motor vehicle administration sites and in senior centers in Maryland. This is a community-based type of driver assessment program. Scientex developed the assessment tool for the National Highway Traffic Safety Administration and it led to the development of software entitled Driving Health, which is a PC-based automated testing system. It is currently being used by the State of Maryland and by Continuing Care Retirement Centers in the mid-Atlantic Region.

In a paper by Charlton, Fildes, Les, and Oxley (2001) the GRIMPS tool was described as a battery of tests that evaluate a number of skills and abilities that are believed to be important for driving tasks, including cognitive and gross motor functioning tests. DMV personnel and other professionals administer the test, which generally takes 15 minutes. The expected outcome of GRIMPS is selfawareness and awareness by friends and family of deficiencies that may impact a person's ability to drive safely.

In Dangerous Driving and Seniors, accessed at http://www.la4seniors.com/, other assessment tools are mentioned. The American Automobile Association (AAA) produces a self-assessment form, Driver 55 Plus: Test Your Own Performance. This form helps drivers identify their limitations. In California, a driver can request that Department of Motor Vehicle staff conduct a private driver 
evaluation. A driver rehabilitation specialist is assigned to a driver to evaluate vision perception, functional ability, and reaction time.

Although not exactly an assessment tool, the AARP has developed a driver education program entitled, 55 ALIVE/Mature Driving Program, which allows older persons to enhance their driving skills while avoiding traffic accidents and violations. Straight and Jackson (1999) note that 34 states and the District of Columbia require insurance premium discounts or reductions in infraction points be awarded to persons who take an approved driving course, such as the AARP's. Nova Scotia also provides a discount on car registrations and drivers' licenses for people 65 years and older if they attend a driver safety refresher course. The course is voluntary and is not required to maintain a license (Service Nova Scotia and Municipal Relations, 2001).

Another assessment tool described in several of the articles and reports is the Useful-Field-of-View Test (UFOV). Medical or psychological professionals often use UFOV to assess visual processes among older persons. Schneider (2002) describes UFOV as a computer-administered and computer-scored test of visual attention. The test assesses declines in visual sensory function, visual processing speed, and visual attention skills. It consists of three tasks, which include measuring central vision and processing speed, measuring divided attention, and measuring selective attention. Central vision and processing speed are measured when the examinee identifies a target object presented for varying lengths of time in the center of the computer's screen. Divided attention is measured when the examinee identifies a central target object in the center of the screen as well as an object displayed in the periphery. Selective attention is measured in a similar manner as divided attention, except the object displayed in the periphery is embedded in distracters. The results from these three tasks are used to determine the examinees UFOV risk level. Owsley et al. (1998), in the Journal of the American Medical Association, provide the results of a study in which they calculate the risk levels of older persons and correlate those levels to crash risks. In the article, the authors note that the older drivers in the study with a 40 percent or greater UFOV reduction were more than twice as likely to have been involved in a motor vehicle crash. 
In the U.S. Department of Transportation report, Improving Transportation for a Maturing Society (1997), the authors suggest that license renewal requirements for older persons vary greatly among the states. The report includes a table that identifies the in-person license renewal intervals and conditions in 1994 for each state; however, the Insurance Institute for Highway Safety posted updated licensing renewal requirements for older drivers at www.hwysafety.org/safety facts/state laws/older drivers.htm. As of January 2003, according to the Insurance Institute for Highway Safety, the majority of states require license renewals every four years. California requires that any person over age 70 must renew his or her license in person. In Illinois, in-person renewal occurs every two years for persons ages 81-86 and every one year for persons age 87 or older. In addition, any person age 70 or older must take a road test at the time of in-person renewal. New Hampshire also requires a road test at the time of in-person renewals for drivers age 75 or older. Maine, Oregon, and Utah have age-related stipulations for vision tests. In Maine, a vision test is required at first renewal after the driver's $40^{\text {th }}$ birthday and at every second renewal until age 62; thereafter, a vision test is required at every renewal. In Oregon, vision screening is required every eight years for drivers 50 and older. In Utah, a vision test is required for people age 65 and older.

Skinner and Stearns (1999) note that doctors and other medical professionals are hesitant about becoming involved in the decision to renew or revoke an older person's license. Many medical professionals would prefer an advisory role rather than an adversarial one. These professionals are concerned that patients will not be honest about conditions if they feel their doctor must report to another entity about those conditions. It seems, however, that the general consensus of the American Medical Association is that public safety is a greater priority over confidentiality of patients. According to Dangerous Driving and Seniors, accessed at www.LA4Seniors.com/driving.htm, in 1999 the American Medical Association changed its ethical guidelines to allow doctors to notify their respective motor vehicle departments about patients with medical conditions that could make them unsafe drivers. The American Medical Association policy E2.24--Impaired Drivers and their Physicians stipulates that physicians should assess patients' physical and mental impairment that could affect driving abilities. It also states that physicians should employ several methods to correct the deficiencies, including medical treatment. However, if efforts to correct the Senior Transportation Alternatives: Why Are They Important and What Makes Them Work? 
impairments are unsuccessful or if there is clear evidence that substantial driving impairments are a threat to patient and public safety, the physician's role is to report the medical conditions to the Department of Motor Vehicles.

Elected officials are also caught between protecting the rights of older persons and preserving public safety. Lobbyists for both seniors and organizations demanding more screening of older drivers scramble for the attention of elected officials. Senior advocacy groups, such as the AARP have successfully thwarted attempts by several states to stiffen the licensing requirements for older drivers.

In a CBC Television presentation (2000), reporter Catherine Clark documented the concerns of several Canadian seniors who questioned the fairness of renewal requirements based on age. Several of the Canadian provinces have additional requirements of seniors, including British Columbia, which requires medical exams for drivers 80 years and older, and Ontario, which requires a reassessment every two years for drivers 80 years and older. Clark interviewed one man who has admitted to noticing that as he has aged, his reflexes are not as quick as they used to be and his eyesight is not as sharp. However, he believes that having testing requirements that apply to persons of a certain age is discriminatory.

Many seniors, such as a 76-year old woman interviewed by CNN (1999), fear they would lose their license as a result of new testing requirements. These seniors fear, if they are no longer able to drive, they will lose their mobility and independence.

\section{Driving Cessation}

Whether an older person has participated in an assessment that revealed visual and motor skills deficiencies, has been influenced by friends or medical providers, or the person begins to question his or her own ability to drive safely, at some point most seniors must consider the options for addressing their ability to drive a motor vehicle safely. Kostyniuk, Trombley, and Shope (1998) suggested in their paper, The Process of Reduction and Cessation of Driving Among Older Drivers: A Review of the Literature, that for older persons the concerns about their driving abilities may be remedied by relying more on 
alternative modes of transportation or reducing their number of trips. For others, that may mean they will stop driving altogether. Driving cessation may be the result of a "long continuous reduction process" or the result of some significant event that leaves a person unable to drive.

The decision to stop driving is an extremely emotional one partly because society equates driving with autonomy and competence (Persson, 1993). Kostyniuk, and Shope (1998) learned through focus groups that older drivers believe driving is related to their independence and convenience. The overall theme in most of the literature related to driving cessation is that driving is directly correlated to independence. The majority of the participants in Kostyniuk and Shope's focus groups had made no plans regarding alternate transportation for the time when they will have to stop driving. For many of the male respondents, the possibility of stopping driving had not even been considered. The participants spoke of their fears as it relates to the time at which they will no longer drive. Those fears include depending on friends and family to get around, not being able to maintain social and civic interests, and the crippling effects (literally and figuratively) of not driving.

Jon Burkhardt, in Mobility Changes: Their Nature, Effects, and Meaning for Elders Who Reduce or Cease Driving (1999), describes the consequences for seniors who reduce or cease driving as personal costs, costs to friends and families, and community or societal costs. He also suggests that further research could reveal correlations between depression and driving cessation. $\mathrm{He}$ hypothesizes, however, based on focus group discussions, that depression is more likely to occur and to be more severe among seniors who are forced to give up driving than among those who voluntarily give it up. He further hypothesizes that those who gradually give up driving before cessation exhibit depressive symptoms less often.

Marottoli et al. (1997) used data from a longitudinal study of community-dwelling seniors to determine whether driving cessation is related to an increase in depressive symptoms. They found that even when accounting for medical and socio-economic factors, driving cessation was found to cause an increase in depressive symptoms. The authors of the study indicate that clinicians and policy-makers need to consider carefully the consequences of their

Senior Transportation Alternatives: Why Are They Important and What Makes Them Work? 
recommendations to older drivers. While not suggesting that clinicians should not be involved in making driving recommendations, they are suggesting that more accurate assessment tools be developed to prevent recommending driving cessation or reduction prematurely.

Premature driving cessation or reduction was the subject of several articles found in the literature review. Wilkins, Stutts, and Schatz (1999) report on the effects of premature reduction and cessation of driving on women. Through previous research, they found that there is a population of women that appear capable of driving, but who drive infrequently or not all. According to Wilkins, Stutts, and Schatz, these women consist of those who never enjoyed driving, who are uncomfortable with traffic or have a retired spouse or partner available to drive them. The methodology used for this study included conducting focus groups with women who voluntarily drive infrequently or who have voluntarily stopped driving, and also included a one-hour on-road driving evaluation.

The focus group discussions revealed that many of the participants were dissatisfied with their current level of mobility and independence. Many wished to drive more, but in limited environments, and many said they lacked confidence in their driving or feared particular aspects of driving. Eight of the focus group attendees participated in the on-road driving evaluation. Four of those eight drove well and additional lessons were not recommended. Three of those eight drove acceptably and safely, but the instructor thought a few lessons might improve their confidence. Finally, one participant made several mistakes that required intervention by the instructor. Although the instructor recommended several lessons, it was unclear whether the lessons would benefit enough to result in safer driving.

In post-study conversations with participants, according to Wilkins, Stutts, and Schatz (1999), many of the participants indicated that their confidence had improved since participating in the study and many had begun to drive more frequently as a result. This supports the authors' hypothesis that many women reduce or cease driving prematurely. 
Transportation Alternatives for Seniors

Most of the literature regarding the importance of mobility for seniors suggests that for older persons, maintaining mobility is crucial to their health and wellbeing. In a March 2001 speech Transportation for an Aging Population, Patricia Waller said, "the strongest predictor of premature death among older people is social isolation."

The Insurance Institute for Highway Safety (2001), in Older Drivers Up Close: They Aren't Dangerous Except Maybe to Themselves, identifies three things that might enable seniors to remain mobile for longer: intersection modifications, vehicle design changes, and improved transportation alternatives.

Intersection collisions are one of the most common crashes for older drivers. Status Report (2002) says that drivers 85 years and older are more than 10 times as likely as 40-49 year olds to be in fatal multiple-vehicle crashes at intersections. This may be because older people may get hurt more easily and are more likely to die as a result of their injuries. High intersection collision fatalities are also due to the fact that many older drivers are deficient in sensory functions that are critical at intersections. Since intersections can be dangerous for everyone, particularly older persons, any improvements will prove beneficial. Specific improvements identified in Status Report were converting two-way stop intersections into four-way stop intersections, installing roundabouts, and installing protected left turn signals at intersections.

The article also suggests implementing vehicle design modifications that will allow seniors to operate their vehicles safely for a longer period of time. The authors suggest that the primary goal in improving vehicle design is to improve occupant restraint and protection systems, as the primary reason that many seniors suffer serious injuries or fatalities in automobile crashes is a result of their fragility. Such improvements include belt force limiters, which are intended to reduce the risk of rib fractures caused by shoulder belt forces. They allow the occupants more "give" and rely more on airbag technology than the standard safety belt system. 
Another change might be to develop improved safety belt systems that distribute forces across more of the body. Some automobile manufacturers have already developed prototypes of a four-point safety belt. Advanced airbag technology is evolving and one such improvement includes a driver or occupant identifier that would signal when an older occupant is in the vehicle. This would allow the airbag to inflate with less force to account for fragility. Finally, vehicle ergonomics addresses how car manufacturers might equip new vehicles with features that are more conducive for older drivers, such as larger controls, nonreflective mirrors, and high-contrast displays.

Insurance Institute for Highway Safety (2001) suggests that the most popular alternatives to driving for seniors involve cars, because the reliance on cars remains strong even after they have stopped driving. Seniors who do not drive themselves often get around as passengers in cars driven by friends and family. The article suggests that mass transit is often not suitable for seniors, because it favors commuters and is not convenient for older drivers.

In contrast, several articles or reports suggest that mass transit is a suitable alternative for seniors, and cite agencies that have implemented steps to improve transportation for the aging population. The American Public Transportation Association (APTA) published a report in 2002 entitled The Benefits of Public Transportation: Mobility for the Aging Population. The report identifies several large public transportation agencies and smaller non-profit providers that are expanding services and implementing enhancements to make public transportation more user-friendly for older persons. Examples include Valley Metro System in Phoenix, Arizona, which has replaced 80 percent of its fleet with low-floor vehicles to ease access for older persons. Valley Metro also is installing automatic bus stop announcers to identify bus stops for riders and deploying neighborhood circulator services that use small vehicles.

According to the APTA report, the transit agency in Des Moines, lowa developed "On-Call" service for older residents. This service allows seniors to make trips between 9 a.m. and 3 p.m. by calling bus drivers directly. A report by the Beverly Foundation (2001), Supplemental Transportation Programs for Seniors, identifies 370 supplemental transportation programs, consisting mainly of grassroots and community-based informal transportation services for seniors. The Beverly

Senior Transportation Alternatives: Why Are They Important and What Makes Them Work? 
Foundation (2001) concurs that their preliminary research revealed that many older Americans could not access ordinary forms of public transportation and, as a result, many communities are relying on these supplemental programs.

Glasgow (2000) notes that the availability, quality, and convenience of public transportation should be increased in order for it to be a reasonable alternative to the motor vehicle. Increased paratransit services are increasingly important, especially in rural areas where significant distances must be covered by seniors to reach goods and services that are generally located in more populated areas.

The Maricopa Association of Governments developed Regional Action Plan on Aging and Mobility (2001), which identifies recommendations for improving transportation options for seniors. The recommendations represent several focus areas, one of which is developing alternative transportation options. The specific recommendations are:

- Establish a transportation consortium to design and oversee a transportation coordinated system for older adults and other transportation limited populations

- Improve transportation information gathering and dissemination

- Expand existing services

- Develop new transportation options

- Promote private sector involvement in providing alternative transportation options to older adults and other special needs populations

- Increase transit use through improved amenities at transportation facilities

- Expand or replicate the existing peer travel-training program

- Encourage legislation that supports funding for transportation coordination efforts

The plan suggests best practices and identifies rationales and roadblocks for each initiative. For instance, the plan suggests that transit amenities, such as shade, restrooms, water fountains, and increased security would make transit more attractive, user-friendly, and functional for older users. Other suggestions include expanding the peer travel-training program to include more volunteers. This program educates people who have never used transit by providing a travel partner to demonstrate how to successfully use the system. 
Bruff and Evans (1999) developed a similar plan for the Michigan State Safety Commission. In the Michigan plan, alternative transportation is also addressed. The authors suggest that fixed-route, demand-responsive, and volunteer resources need to be better coordinated to maximize service and quality. In addition, the plan suggests that specific improvements to each of these public transportation resources are needed. For instance, fixed-route service should be ensured along areas of high-density older populations or elderly attractions and amenities and service frequency should be increased along identified highpriority corridors during off-peak periods. This is in contrast to the thought that service frequency can be reduced between peak-hour periods, since commuters have less need for service. Older persons tend to travel during the off-peak period and often prefer service as frequent as the commuter. The plan also notes that more direct service between residential areas and senior-frequented activities is desirable. Just as the Maricopa plan suggests, Bruff and Evans note that amenities along high-priority corridors can make transit travel more comfortable, accessible, and safe for older passengers. 
Senior Transportation Alternatives: Why Are They Important and What Makes Them Work?

Page 24 


\section{Chapter Two \\ Summary of Focus Groups}

While the literature review provided an overview of issues related to senior driving, focus group discussions were held to allow seniors the opportunity to corroborate the literature review findings. The focus groups allowed NCTR to explore the range of perceptions and concerns that seniors have regarding driving and making the decision to cease driving.

\section{Focus Group Methodology}

Four focus groups were conducted with senior citizens 65 years and older to explore senior attitudes regarding driving and alternative forms of transportation. Each group was conducted in a distinct region of the state in an attempt to maximize the diversity of participants and to obtain a representative characterization of seniors statewide. In addition, seniors representing various economic and social backgrounds were involved to ensure diversity. All of the sessions were tape-recorded and the assistant focus group moderator compiled detailed notes during each meeting.

Participants were recruited through Area Agencies on Aging with assistance from the Florida Department of Elder Affairs. After selecting the geographical areas where the focus groups would be conducted, contact was made with the Area Agency on Aging in the respective counties. Representatives from the Area Agencies on Aging were provided with a description of the overall project and specific details about the focus groups and the recruiting guidelines.

The only recruiting stipulation was that participants were required to be 65 years of age or older. Each agency's representative first asked potential participants if they would be interested in participating in a group discussion on seniors, driving, and transportation issues for a research study. Those who agreed were then contacted by the focus group moderator via telephone and invited to attend the session being held in their city. This point of contact aided in establishing a rapport between the participants and the moderator. 
The focus group sessions were limited to a two-hour time block, and the topical discussion lasted approximately one and one half hours. Group members were first informed of their rights as participants in a research study and each participant read and signed an approved informed consent form. Copies of the signed form were made available to each participant. Participants also completed an anonymous and confidential demographic information form for statistical and classification purposes.

A single questioning route for the four focus groups was developed based upon the results of the literature review. Recurring themes and transportation issues found to be of significant importance to senior citizens in the literature were used to compose the focus group questions and in-depth probes. Because recruiting guidelines did not account for participants' licensing or driving status, questions were structured to foster discussion with non-drivers as well as drivers.

A transcript of each focus group interview was created from audiotapes of the sessions. These transcripts were analyzed to determine themes within and among the focus groups. Each focus group transcript was summarized, and is presented with illustrative quotations from study participants in the appendices. This section includes a summary of the cumulative results of the four focus groups.

\section{Demographic Information}

A total of 31 senior citizens participated in the four focus groups. Fourteen participants recorded their age in the 76 - 85 years category; 13 reported their age to be between 65 and 75 years; and two were 86 years or older. One participant was between the age of 55 and 64 years, which is outside the screening parameters for the study. One participant did not respond to this question.

There were 21 female participants and ten males. Ethnicity was self-reported, and 22 participants characterized themselves as white or Caucasian using a variety of descriptions such as Irish-American, American, or Italian. Three participants classified themselves as black or African-American; two classified themselves as Hispanic; and one participant was Pacific Islander. 
With regard to marital status, 17 participants reported that they are widowed; ten stated they are married; one is divorced; and one participant did not respond to this question. Fourteen of the participants reported that they live in one-person households; 11 reside in two-person households; two live in three-person households; and one participant did not respond to this question. Within their households, 15 participants have one working vehicle; seven reported that they have two working vehicles; six have no working vehicles; and two participants did not answer this question. Twenty-nine participants reported that they are yearround Florida residents and two did not respond to this question.

Twenty-one of the participants reported that they drive and ten claimed they either never drove or have given up driving. With regard to the age at which they first began driving, 15 participants claimed they were driving at age 18 or younger; ten began driving between the ages of 19 and 30; and one began driving between the ages of 31 and 50 years. Five participants did not respond to this question.

With regard to occupation, 22 of the participants are retired; three are housewives; two participants reported that they work outside of the home; one participant reported that he/she is disabled; and one participant did not respond to this question.

Total household income for 2002 was distributed among participants as follows:

- \$0-4,999; one participant

- $\$ 5,000-9,999$; three participants

- $\$ 10,000-14,999$; one participant

- $\$ 15,000$ - 19,999; two participants

- $\$ 20,000$ - 24,999; two participants

- $\$ 25,000$ - 29,999; three participants

- $\$ 30,000$ - 34,999; two participants

- $\$ 35,000$ - 39,999; two participants

- $\$ 40,000-44,999$; two participants

- $\$ 45,000$ - 49,999; one participant

- $\$ 50,000$ or more; four participants

Eight participants did not respond to this question.

Senior Transportation Alternatives: Why Are They Important and What Makes Them Work? 
Seniors and Driving

Participants were first asked to discuss their opinions of senior drivers. The topic of safe driving was mentioned immediately in each of the four focus groups. Some participants expressed concern that seniors are often unable to maintain their capabilities in driving as they age. This perception is typically related to the many physical changes that may happen as one ages, such as deteriorating eyesight, slowing reflexes, hearing loss, and arthritis. Many group participants noted that they know seniors whom they believe should no longer be driving because deteriorating mental and/or physical conditions pose a threat to themselves, their passengers, or others on the road.

A number of participants indicated they are confident in senior drivers, most particularly themselves. Some expressed the opinion that seniors are much safer drivers than are younger people because they maintain speed limits, are generally cautious and conscientious, do not take as many risks while driving, and they are typically courteous drivers.

Several participants discussed their fears related to other drivers, most notably younger or speeding drivers. Some participants expressed displeasure at what they perceive to be societal stigmatization of older drivers as slow or inept. They generally believe that such attitudes, in addition to the stresses of contemporary life, make for aggressive and dangerous drivers. A few also mentioned that they notice many drivers not utilizing their turn signals, creating a potentially hazardous situation. Night blindness caused by the headlights of passing vehicles and streetlights was also discussed as a problem for many participants.

In addition to assessing themselves and other drivers, many of the participants who drive explained that road features often do not contribute to safety, particularly for senior drivers. Several participants suggested the improvement of signage by increasing the type size so that drivers of all ages and visual abilities could easily read the signs at highway speeds. The placement of road signs was also discussed as a safety factor. A number of the senior participants expressed the desire for advanced notice of turn lanes and street names at intersections so that drivers have adequate time and space to move into the appropriate lane.

Senior Transportation Alternatives: Why Are They Important and What Makes Them Work? 


\section{Changes in Driving Habits}

Concerns for safety while driving have led most of the participants to make changes in their driving habits as they have aged. The most commonly cited change that participants have made is a reduction or cessation of nighttime driving. Many participants noted that their vision has deteriorated somewhat with age and they are often affected by night blindness. Several have therefore made the decision not to drive at night. While a few mentioned that this has negatively impacted their ability to participate in nighttime activities, many participants stated they are content to be at home in the evenings, mostly because they do not have anything to do after dark.

Several focus group participants noted they and many of the senior drivers they know often only travel on familiar routes, particularly if they must drive at night. In addition, some of the participants reported they have slowed their driving speeds as they have aged. This is typically related to their belief that reflexes diminish with age, and they feel less confident in their ability to react quickly to road hazards.

The AARP Driver Safety Program was mentioned by many of the focus group participants. All of the participants who have participated in the program claimed that it has been extremely valuable in reminding them of safe driving skills and suggesting or encouraging some of the changes they have made in their driving habits. An additional benefit of the program to many of the participants is that completion of the course warrants a decrease in automobile insurance premiums for seniors.

\section{The Non-Drivers}

Ten of the focus group participants reported that they either never drove or they no longer drive. Their transportation needs are met in a variety of ways, including family, friends, and senior center services. The majority of those who are not driving came to the decision themselves or in consultation with family members. For many, health-related concerns prompted the cessation of driving. Some participants reported near accidents or generally uncomfortable feelings

Senior Transportation Alternatives: Why Are They Important and What Makes Them Work? 
related to slowing reflexes. A few of the participants stated that fear is one of the reasons they do not drive. They claimed that traffic congestion has worsened in the last few years and that people are fast and aggressive drivers, making driving difficult for many seniors.

Non-driving participants responded positively overall when asked about their quality of life. Most stated they are able to access the goods and services they require, and are generally satisfied with the availability of transportation. It should be noted, however, that eight of these ten non-drivers were participants in Focus Group Number Four, which was held at a senior center that provides extensive transportation services to its clients. These participants are extremely pleased with the services offered to them. They praised the skills and level of care they receive from the drivers, noting that many are like family to them and this provides them with a feeling of security. The other two non-driving participants rely upon family for their transportation needs, and reported to be satisfied with this situation. In contrast to the fears of those who still drive, nondrivers claimed to be independent and quite pleased with not driving. Some participants did note that by not driving, however, they are unable to visit other parts of Florida and family in other states as much as they once did.

While these participants are especially pleased with their access to transportation, participants in all of the focus groups noted that they are aware of seniors who do not leave their homes very often or who have a difficult time meeting basic needs because of a lack of transportation. Some of the participants in Focus Group Number Four noted that prior to becoming involved with activities at the senior center and having access to the center's transportation they often remained at home, watched excessive amounts of television, were isolated from others and enjoyable activities, and were frequently depressed. It is noteworthy that these are many of the negative factors that the participants who continue to drive associate with not driving.

\section{Driving in the Future}

Most of the participants who drive are not at all looking forward to the time they are no longer able to drive. A few asserted they are so insistent upon driving that it will be difficult for anyone to convince them they should stop driving. Many of 
the participants, however, acknowledge that physical limitations may one day prohibit them from being safe drivers and that they may be forced to consider alternatives to driving.

The primary reason participants stated they are anxious about the possibility of not driving in the future is a fear of the loss of independence. Autonomy in transportation and other decisions is closely associated with most seniors' concept of independence and aging with dignity. Most seniors do not want to feel as if they are burdening others, particularly their children or grandchildren, with their needs. Participants asserted that it is an issue of great pride to maintain one's independence through the aging process, and access to transportation, relatively on their own terms, is integral to doing so. Several participants expressed the opinion that access to transportation is as important a quality of life issue as are health and income.

Many study participants who do not drive indicated that although they sometimes ride with friends or family, they typically travel with them when asked, and will only request a ride if it is necessary. Those in focus group number four generally prefer to utilize the transportation services of the senior center. Many of these participants noted that their independence has been enhanced by their access to the senior center's transportation services. Despite the positivism expressed regarding their quality of life, these participants shared similar opinions regarding transportation and independence, noting that the senior center services are the only means they have of maintaining their transportation independence.

Despite strong concerns related to independence and a positive quality of life, most of the participants who drive acknowledged the possibility of not driving in the future. In consideration of alternatives to driving, many participants claimed they are uncertain as to what they will do if they face the challenge of not being able to drive.

Among the alternatives discussed, those most favored are options that provide the senior traveler with choice, convenience, safety, comfort, and dignity. Services such as those provided by the senior center in Pembroke Pines (focus group number four) and the community transportation service available to 
residents of Brevard County (focus group number three) received the greatest overall favor among participants.

Friends and family were also considered to be a potential resource for seniors who do not drive. It is with this alternative, however, that concerns related to independence are greatest. Furthermore, some participants noted that family may not live nearby to assist, and friends are not always available or able to provide a ride.

Some participants considered taxis to be an ideal alternative, contending that the annual cost of using taxis would be equivalent or a savings as compared to automobile ownership. While other participants concurred that taxis are a desirable option, several noted that they are too expensive for seniors to use as their primary means of transportation.

A few participants cited paratransit services as useful for seniors who are unable to drive. Some participants reported they have used paratransit services in Florida or in other areas and have been satisfied with their experiences, particularly with the door-to-door aspect of such services. Paratransit vehicles were also noted to be able to accommodate seniors with physical limitations.

Although fixed-route bus service was mentioned during all of the focus group sessions, it was generally participants' least favored alternative. Many participants stated that it is not a viable transportation option for a variety of reasons such as inconvenient scheduling, infrequency, limited routes, and personal physical limitations in accessing the bus stop and boarding and alighting the vehicle. Many participants expressed an overall willingness to utilize fixed-route bus service if it was more convenient and bus stops were relatively easy to access.

With regard to how seniors learn about the options that are available to them, study participants noted that word of mouth is the most common medium of information among seniors. Doctors, telephone books, newspapers, and television were also mentioned as potential sources of information. Many participants agreed there is a general lack of information among senior citizens regarding what transportation services are available to them. Several 
participants expressed the opinion that such information should be readily available and easy for seniors to locate.

\section{Driving and Decision-Making}

Many of the study participants, regardless of their driving status, believe that senior drivers are capable of assessing their physical and mental conditions and determining their fitness to drive. Other participants, however, argue that not all seniors are capable of self-assessment and that other parties, such as the state or personal physicians, should be involved with in evaluating one's fitness to drive.

Most participants agreed that eyesight should be tested more frequently. While some participants believe older senior citizens should be tested regularly, others contend that all drivers, regardless of age, should be required to have their eyesight tested at regular and frequent intervals. Some participants mentioned regular testing for hearing as well.

Several participants stated they would be comfortable discussing their future driving decisions with family members or physicians. Some of the non-drivers had discussed their decision with family members, but none of the participants reported having such conversations with their doctors. Some asserted they would not support states or governmental regulators being involved with the assessment of senior drivers, while a few participants claimed it is within a state's rights and responsibilities to protect its citizens from unsafe drivers. Overall, however, most of the participants agreed that a senior should be allowed to decide for him or herself when and if the time has come to stop driving. 
Senior Transportation Alternatives: Why Are They Important and What Makes Them Work?

Page 34 


\section{Chapter Three \\ Survey of Senior Transportation Providers}

Chapter Three includes the results of a written survey to identified senior transportation providers. The purpose of the survey was to collect information related to the strategies and effectiveness of programs designed to provide alternative transportation options for seniors.

The original intent of this report was to identify driving cessation programs that target seniors. However, early in this research project it became clear that while there are senior transportation programs created to provide alternatives to seniors who no longer drive, very few are touted as driver cessation programs. Instead, most of these programs are categorized as programs that provide alternatives for those seniors who no longer drive or have reduced their amount of driving. Many in the field, as well as the seniors participating in the focus groups acknowledged a negative connotation associated with the phrase "senior driver cessation." Instead, programs advertised as alternatives to driving for seniors are much better received.

NCTR used a myriad of methods to identify senior transportation programs, including internet and literature searches. Researchers also learned about many programs through seniors participating in the focus group discussions summarized in Chapter Two.

The initial search resulted in the identification of over 90 programs throughout the United States. NCTR acknowledges that there are hundreds of similar programs throughout the country and internationally. The original database of senior transportation programs included program names, staff contact information, and brief descriptions of each program. This database was then used to create a recipient list for the written survey described below.

A multiple choice and short-answer survey was developed based upon the findings of the literature review and the focus groups conducted with senior citizens. The purpose of the survey was to determine the specific components of transportation programs designed for seniors who have reduced or ceased driving. The surveys were sent by mail to 92 senior transportation services 
providers, and a total of 42 completed surveys were returned, yielding a 46 percent return rate. The survey consisted of 37 questions exploring a range of topics related to senior transportation services, such as the types of services provided, the clientele that are served, a service's fleet, its staff, procedures, and funding. A copy of survey instrument will be included in appendices of the final report.

The organizational structures of the individual programs are presented in Figure 1. Sixty-nine percent of respondents (29) reported their agencies are non-profit; 31.0 percent (13) reported to be volunteer organizations; 28.6 percent (12) are local government operated; and 2.4 percent (1) were reported as "other." None of the survey respondents indicated theirs is a for-profit business.

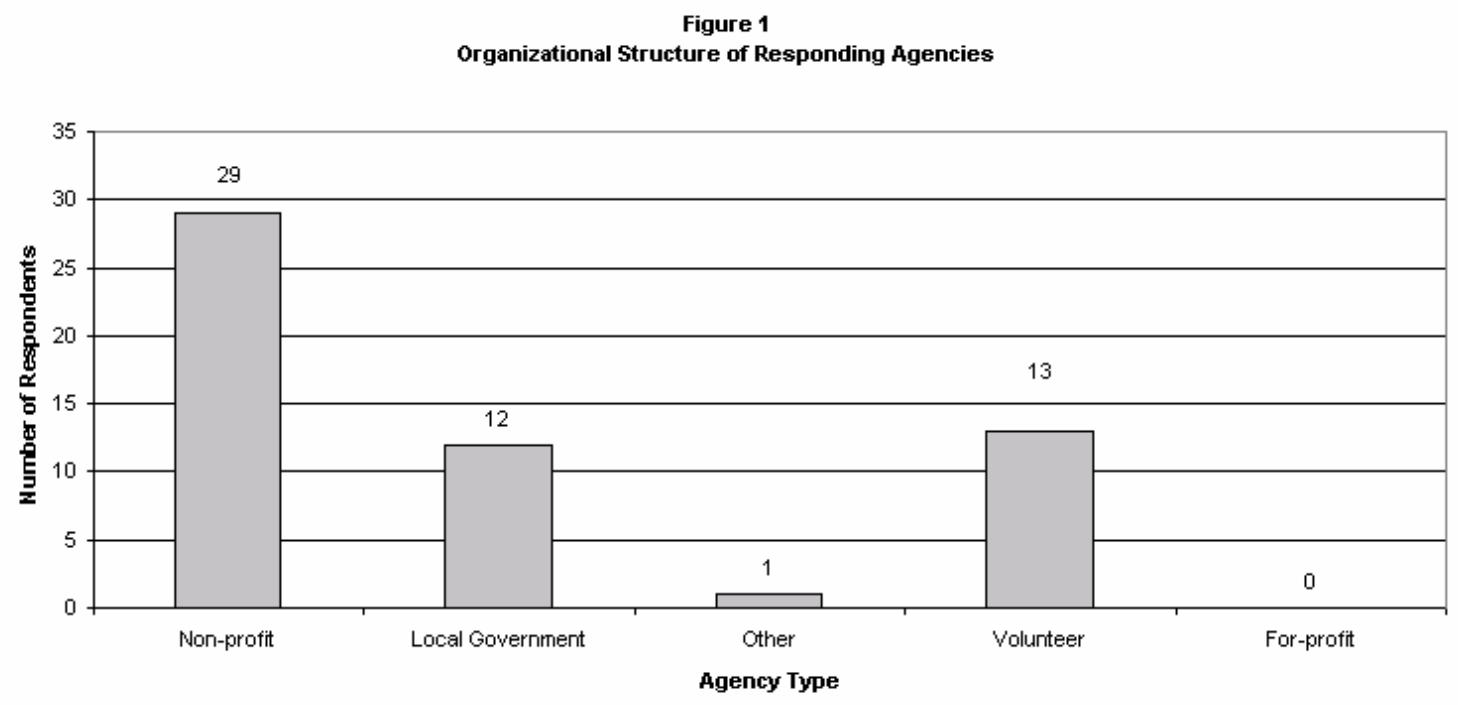

With regard to the service area each organization covers, Figure 2 indicates that 26.2 percent of respondents (11) claimed a service area between 301 and 600 square miles; 19.0 percent (8) cover a service area of 100 square miles or less; 16.7 percent of respondents (7) reported their agencies serve $101-300$ square miles; 7.1 percent (3) reported a service area between 1,001 and 2,500 square miles; and 4.8 percent of respondents (2) claimed a service area of 601 to 1,000 square miles. Outliers included one organization with a service area of 4,028 square miles, and another with a service area of 7,200 square miles. Slightly more than 20 percent of participants (9) did not respond to this question. 


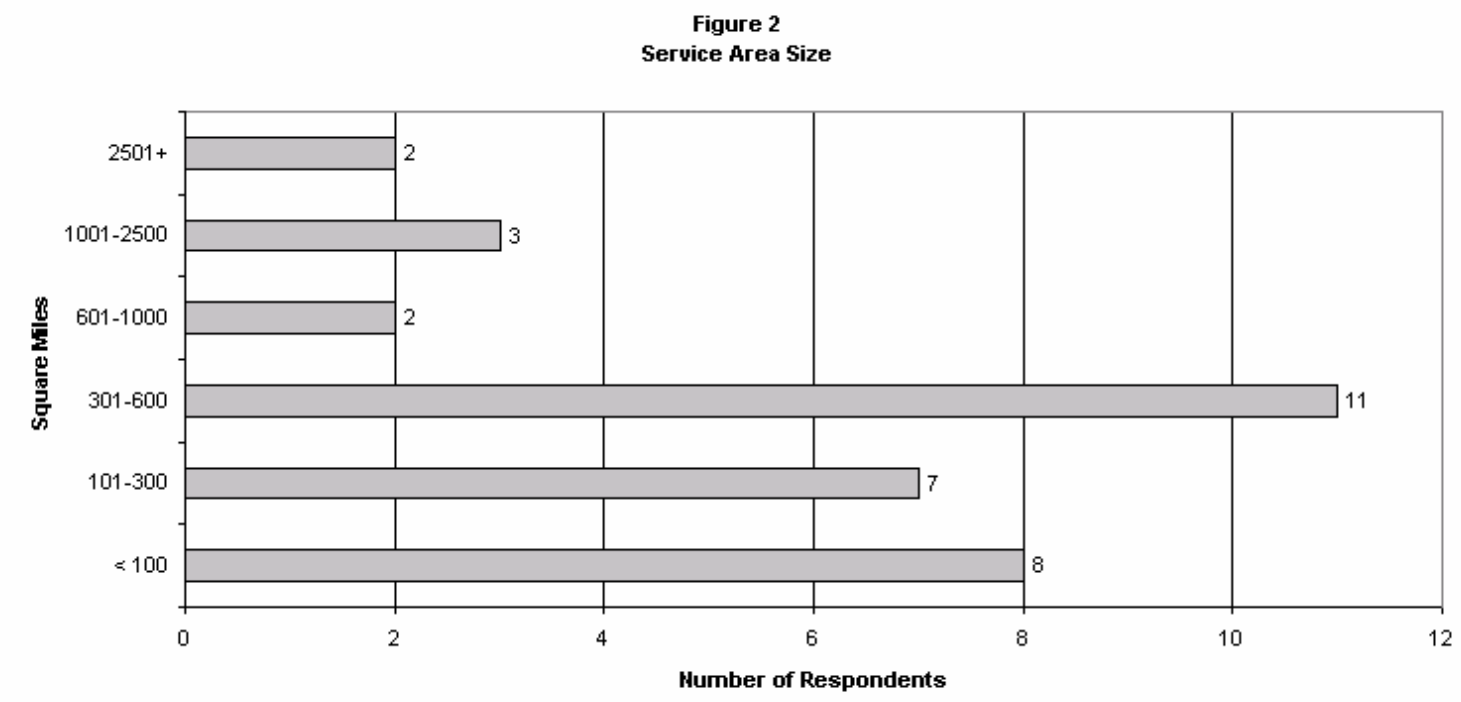

The service area populations of the participating programs, represented in Figure 3 , ranged from less than 5,000 to greater than one million persons. Thirteen of the survey respondents (31.0 percent) reported their service area populations to be less than 50,000 persons; 14.3 percent (6) reported a service area population greater than 500,000 persons; 11.9 percent of survey respondents (5) claimed their service area populations to be 50,000 - 100,000 persons; 11.9 percent (5) claimed their service populations to be 100,000 - 200,000 persons; and 11.9 percent (5) of survey respondents reported service populations greater than 200,000 and fewer than 300,000 persons. Slightly more than seven percent of participants (3) claimed their service area populations to each be 300,000 500,000 persons. Five survey participants did not respond to this question.

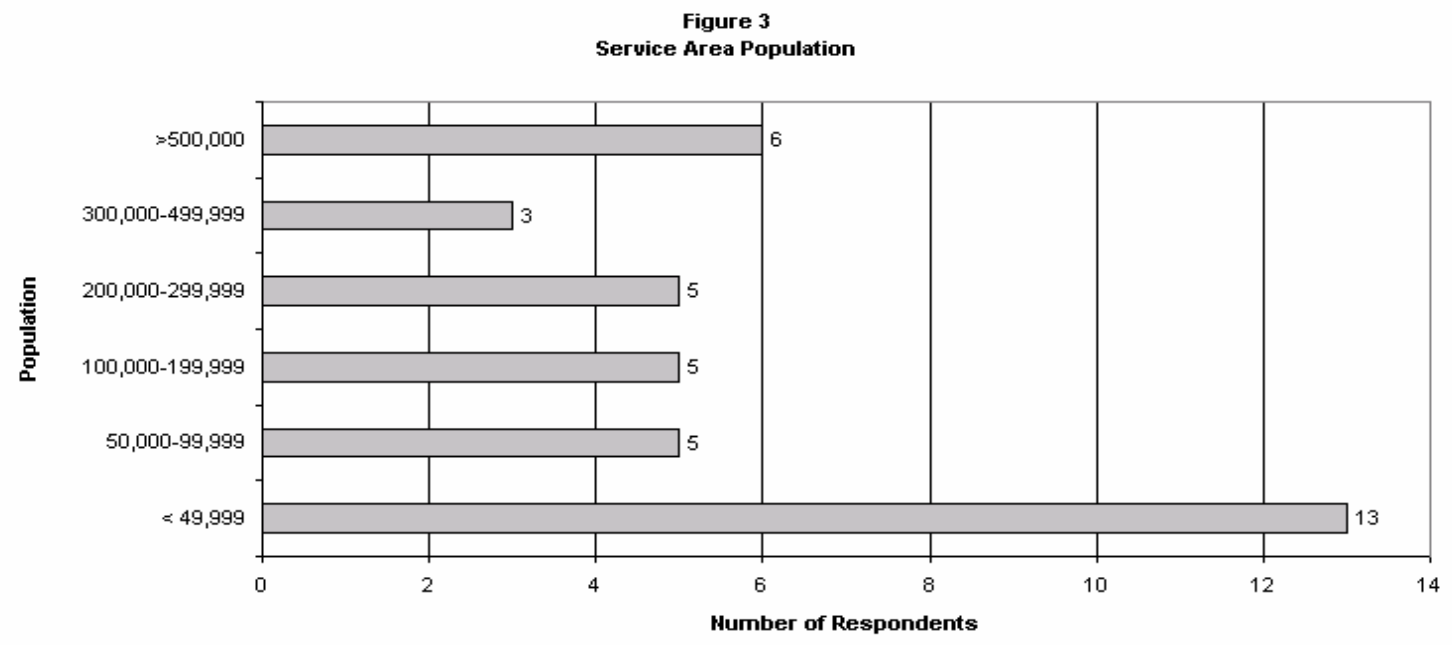

Senior Transportation Alternatives: Why Are They Important and What Makes Them Work? 
Survey participants were also queried as to the types of services their organizations provide, and Figure 4 represents these data. Nearly 80 percent of the responding agencies (33) provide door-to-door transportation service; 47.6 percent (20) provide curb-to-curb transportation service; 42.9 percent of respondents (18) provide support services for seniors; 9.5 percent (4) offer travel training; 4.8 percent of responding organizations (2) provide decision-to-drive counseling; 7.1 percent (3) offer taxi service; one respondent (2.4 percent) reported offering driver skills assessment/evaluation; and one (2.4 percent) reported transportation scheduling only. Eleven respondents (26.2 percent) categorized some aspect of their services as "other," including field trips, meals programs, demand response, shopping escorts, bus passes, respite care, and handyman services.

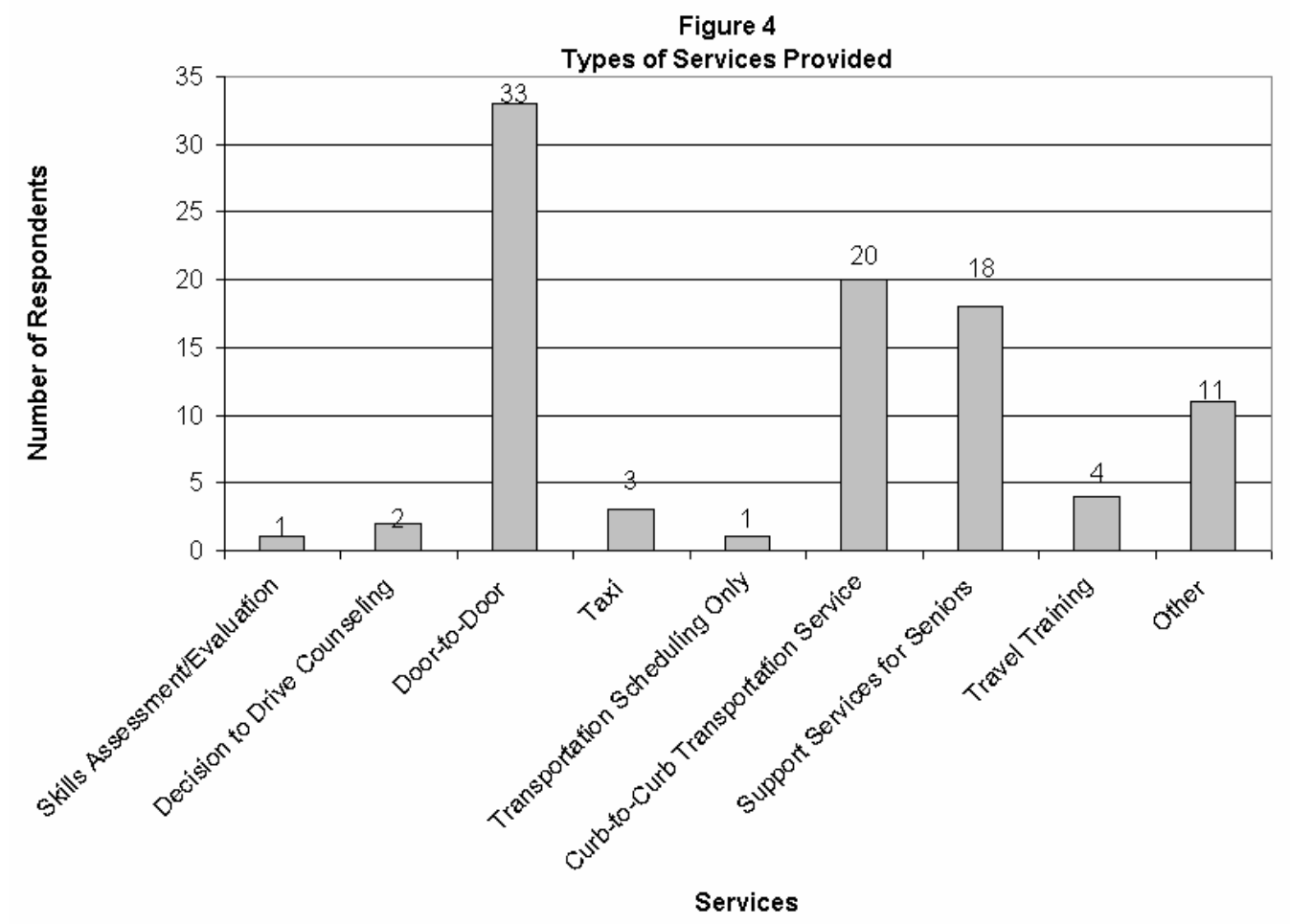

Senior Transportation Alternatives: Why Are They Important and What Makes Them Work? 
With regard to the spans of service provided by the responding organizations, most programs (24, or 57.1 percent) are Monday through Friday operations. Ten other organizations (23.8 percent) provide Saturday service, and seven respondents (16.7 percent) reported the existence of Sunday service. Transportation services typically begin between 7:00 am and 9:00 am (26, or 61.9 percent of respondents), and end between 3:00 pm and 6:30 pm, with several (17, or 40.4 percent) stopping service between 4:30 pm and 5:00 pm. Other programs have variable spans of service, such as Tuesday through Thursday only or variable times. Two survey respondents (4.7 percent) reported that their organizations provide service 24 hours a day, seven days per week, and two participants (4.7 percent) did not respond to this question.

Nearly 48 percent of survey respondents (20) reported theirs to be the only organization providing such services to seniors in their area. Twenty-one of survey respondents (50.0 percent), claimed theirs is not the only organization providing such services, and one participant (2.4 percent) did not respond to this question. This distribution is illustrated in Figure 5.

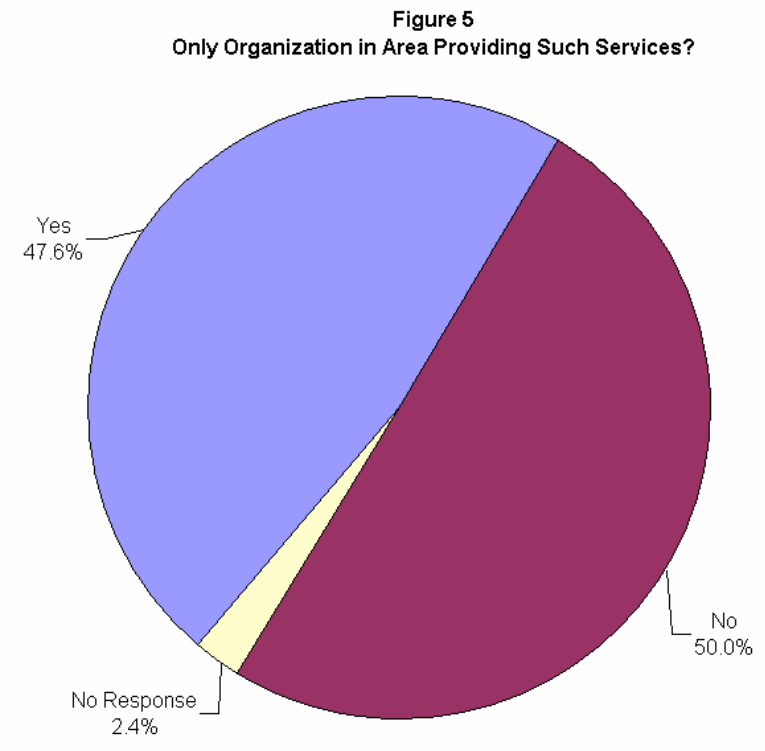

Senior Transportation Alternatives: Why Are They Important and What Makes Them Work? 
As shown in Figure 6, most responding organizations (12, or 28.6 percent) have been providing services for 11 to 20 years; and a significant number (9, or 21.4 percent) have been providing senior transportation services for 21 to 30 years. Eight survey respondents (19.0 percent) reported that their organizations began providing services between six and ten years ago; and 8 respondents (19.0 percent) claimed their organizations have been providing senior transportation services for more than 30 years. Five participants (11.9 percent) reported that their agencies initiated service within the last five years.

Figure 6

Length of Service

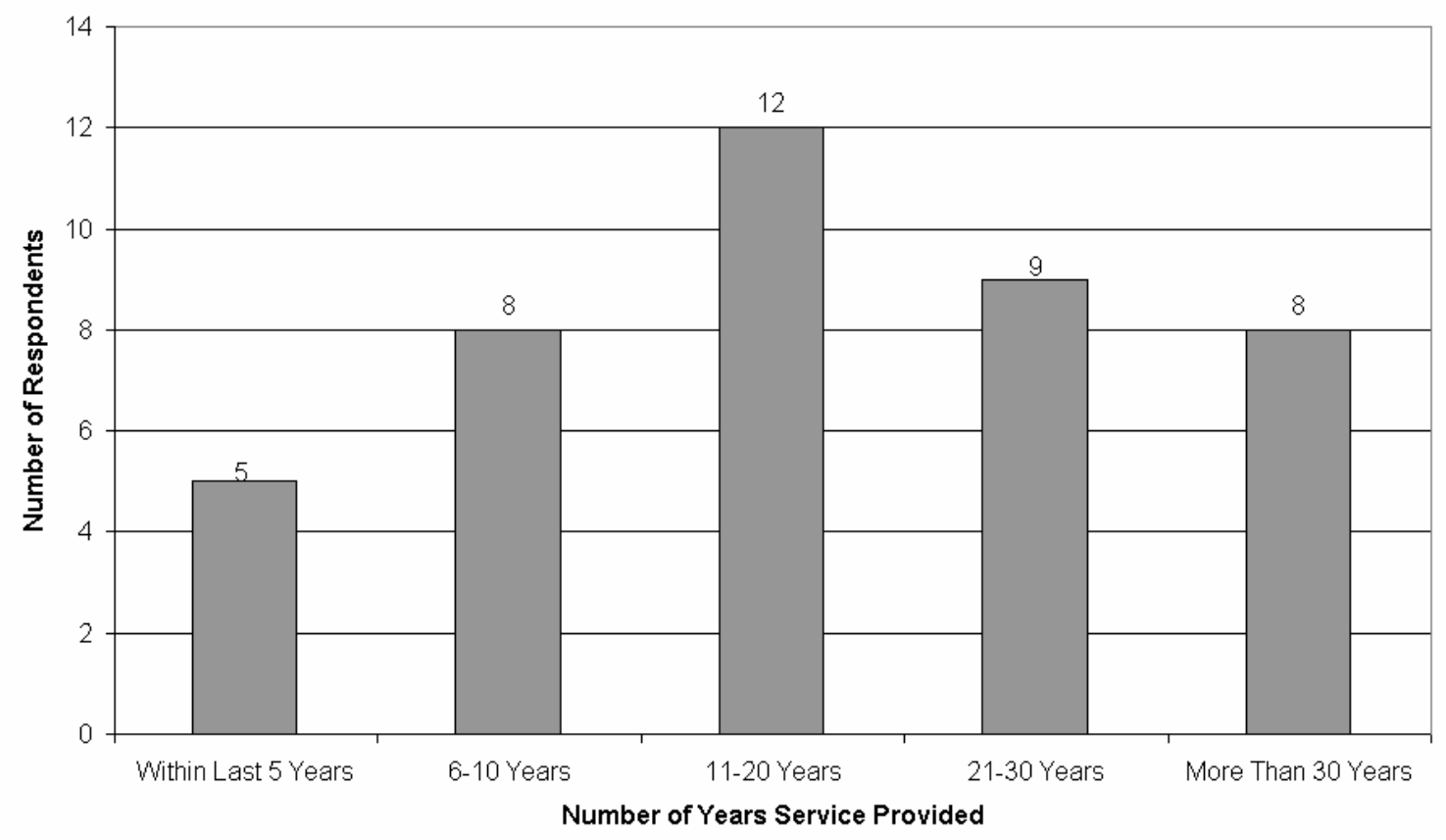

Most of the respondents (25, or 59.5 percent) claimed their mobility service programs were not modeled after another program; while 11 (26.2 percent) declared their programs were modeled after another in design. Six survey respondents (14.3 percent) reported they did not know whether their organization had used another program as an example.

With regard to the availability of fixed-route transit service, 69.1 percent of survey respondents (29) reported that it is available in the areas served by their 
organizations. As shown in Figure 7, the remaining participants (12, or 28.6 percent) declared there is no fixed-route transit service in those areas served by their organizations. One respondent did not provide an answer to this question.

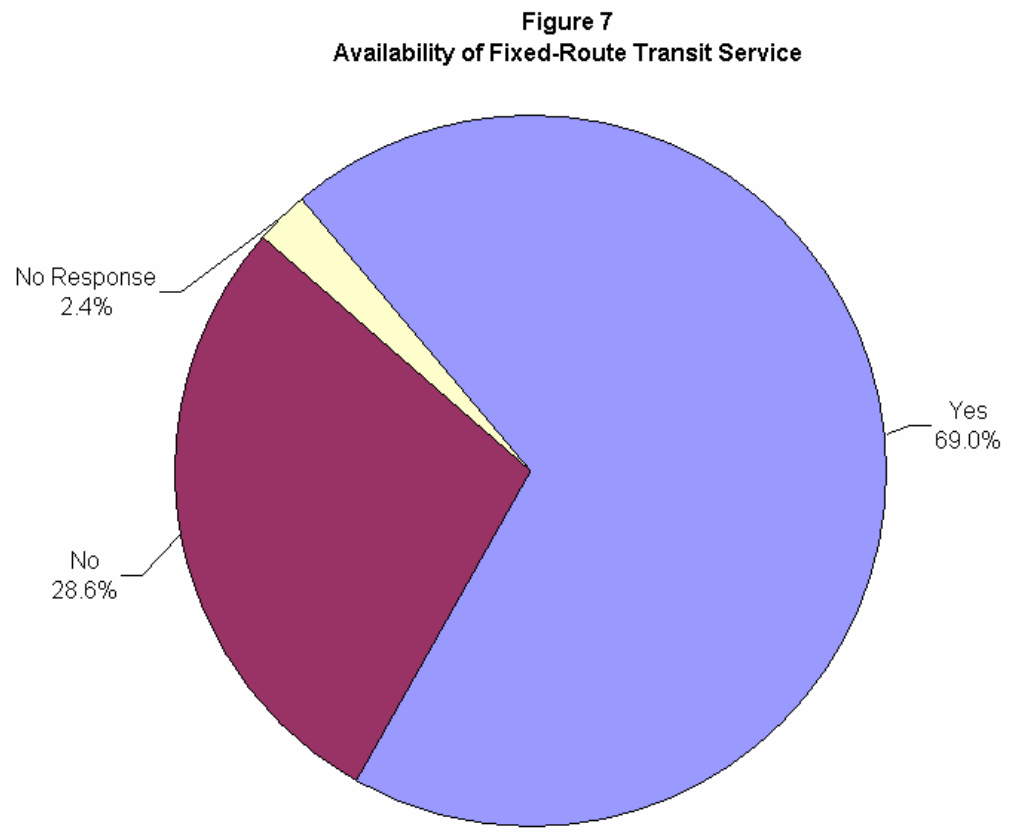

\section{Clientele}

Many of the organizations responding to the survey (18, or 42.9 percent) serve less than 1,000 clients per year. Thirteen respondents (31.0 percent) reported their agencies serve between 1,000 and 4,999 clients per year; 9.5 percent (4) serve 5,000 to 9,999 clients per year; and six participants (14.3 percent) reported their organizations serve more than 10,000 clients each year. One participant (2.4 percent) did not respond to this question.

Survey participants were also queried as to the composition of their clientele. As shown in Figure 8, 100 percent of survey respondents (42) reported their program provides services to senior citizens. Twenty-nine participants (69.0 percent) also reported that "disabled" describes their clientele. Half of the survey respondents (21) cited "economically disadvantaged" as an apt description of 
their clients; and 26 participants (61.9 percent) described their clientele as "those who do not drive." Six survey respondents (14.3 percent) indicated their services are available to "anyone," meaning there are no specific criteria for becoming a client. Seven participants (16.7 percent) also classified their clientele as "other."

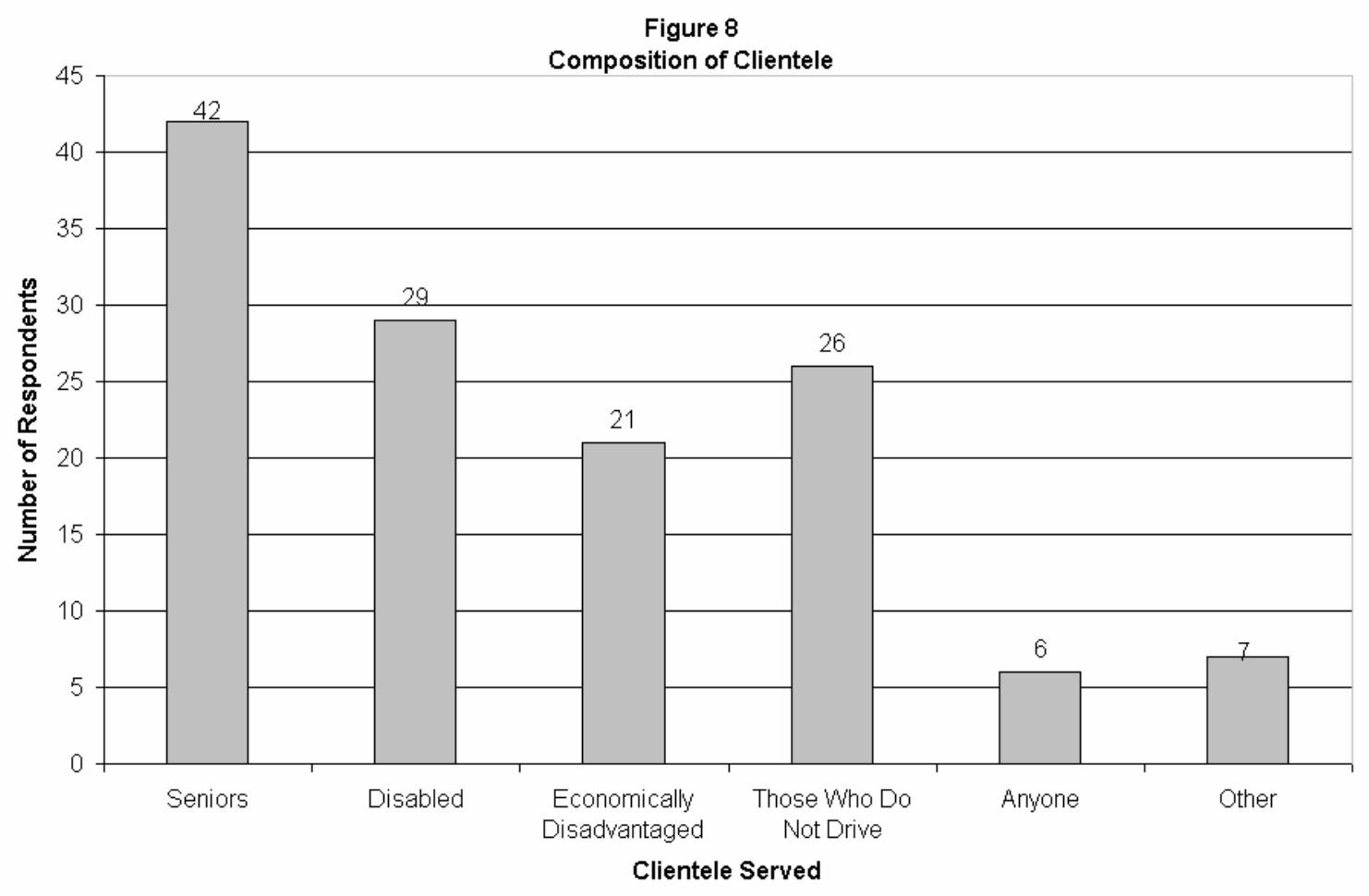

Senior Transportation Alternatives: Why Are They Important and What Makes Them Work? 
Figure 9 illustrates the percentage of clientele age 65 years and older. Twentyeight respondents (66.7 percent) estimated that clientele age 65 years and older represent between 75 and 100 percent of their total clientele. Nine respondents (21.4 percent) estimated $50-74$ percent of their clientele to be age 65 years and older; four (9.5 percent) estimated it to be $10-24$ percent; and one respondent (2.4 percent) estimated less than 10 percent of his/her program's clientele are age 65 years and older.

Figure 9

Percentage of Clientele Age 65 Years and Older

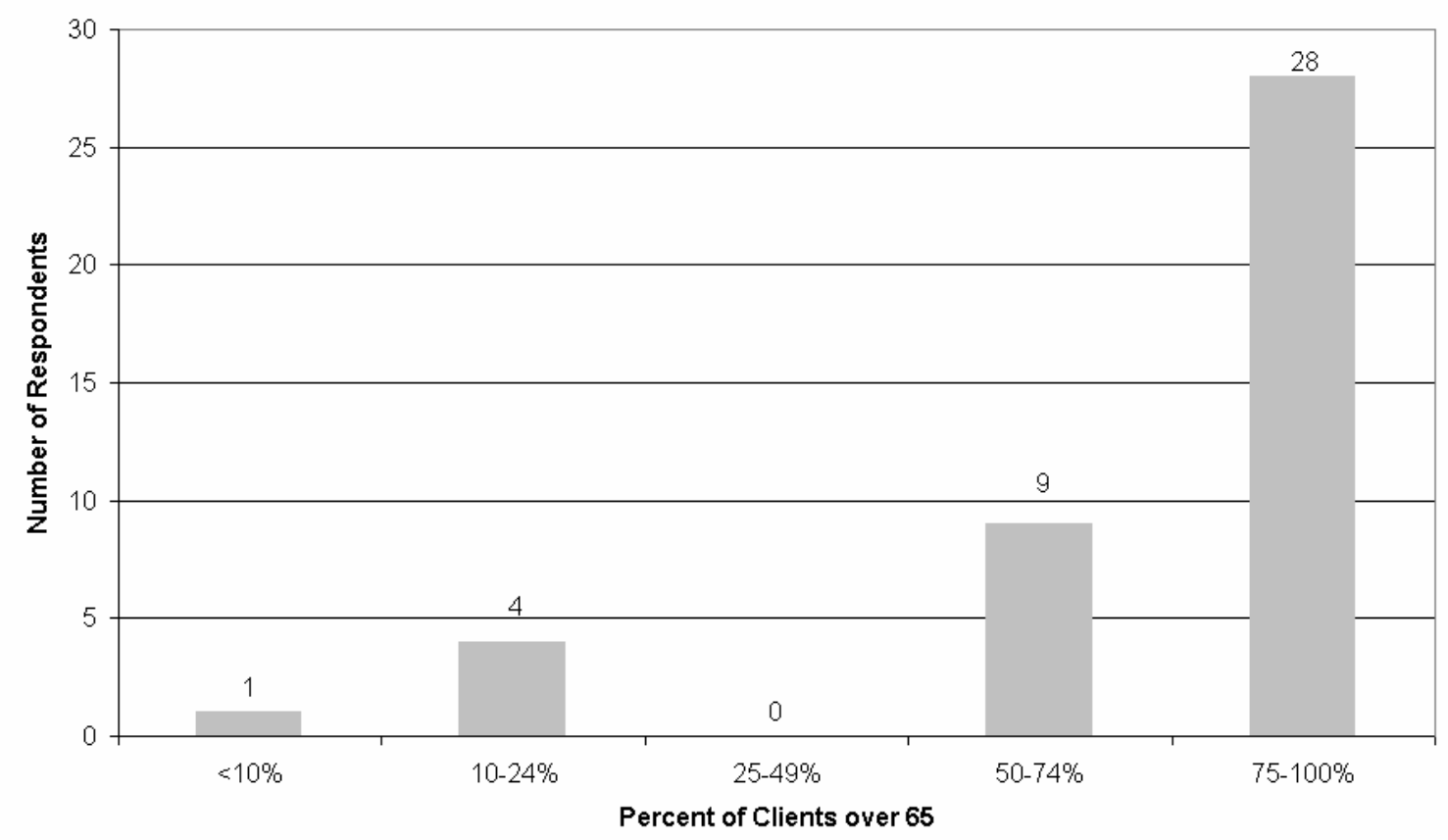

Most of the survey respondents (26, or 62.0 percent) reported that clients must be registered with their organizations in order to use the mobility services offered; while 16 (38.1 percent) reported that clients are not required to be registered with the program. A majority of the programs (34, or 81.0 percent) have established eligibility criteria for clients who wish to use their services; seven (16.7 percent) do not. One participant (2.4 percent) did not respond to this question. 


\section{Fleet}

Participants were asked to describe the vehicles in their organizations' fleets if they provide transportation services. The fleet sizes of the responding organizations are presented in Figure 10. Nearly 48 percent of the respondents (20) reported that their organizations have less than 10 vehicles; six (15 percent) claimed they maintain between 10 and 24 vehicles; three ( 7.5 percent) reported $25-49$ vehicles; two participants (7.5 percent) also reported $50-74$ vehicles; and one participant (2.4 percent) reported between 75 and 99 in the fleet of his/her organization. Ten participants (20 percent) did not respond to this question.

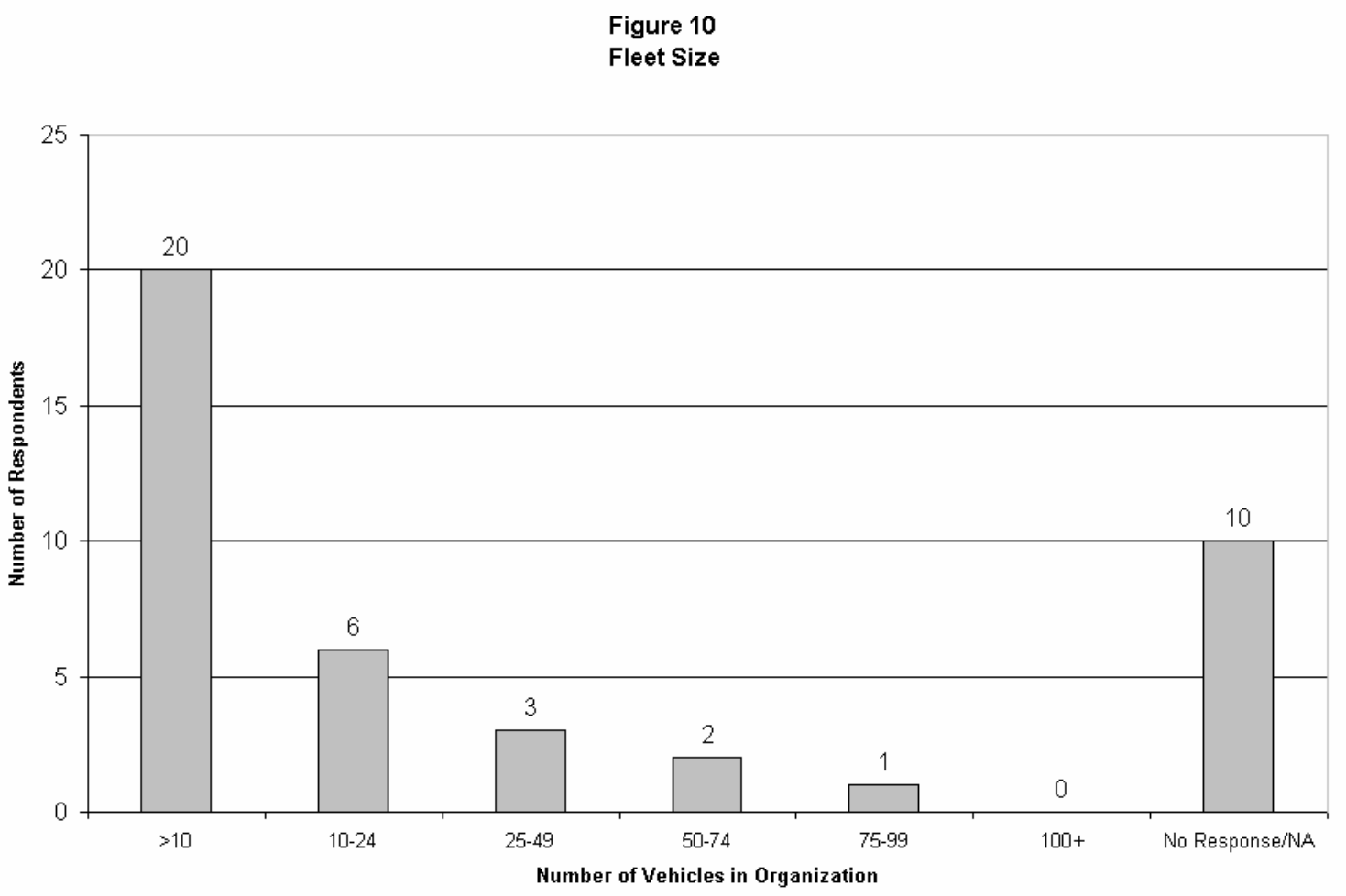

With regard to the types of vehicles used by the organizations, vans are the most common, reported to be used by 21 (50 percent) of survey participants. Buses are used by 11 (26.2 percent) of responding organizations; 10 (23.8 percent) utilize sedans; six (14.3 percent) use cutaways; and three participants (7.1 
percent) reported the use of other vehicles. Eight participants (19.0 percent) did not respond to this question.

Several agencies responding to the survey (17, or 40.5 percent) travel less than 100,000 vehicle miles per year. Nine (21.4 percent) reported traveling 100,000 199,999 vehicle miles per year; three (7.1 percent) claimed to travel 200,000 299,999 vehicle miles per year; two respondents (4.8 percent) claimed 300,000 399,999 vehicle miles; one participant (2.4 percent) reported 400,000 - 499,999 vehicle miles; and 11.9 percent of survey respondents (5) claimed to travel more than 500,000 vehicle miles per year. Five participants (11.9 percent) did not respond to this question.

\section{Staff}

When queried about staffing, 15 survey respondents (35.7 percent) reported that their organizations have less than five full-time vehicle operators. Five participants (11.9 percent) reported having $5-15$ full-time vehicle operators; two (4.8 percent) reported staffing $16-50$; and two participants (4.8 percent) reported having $51-80$ full-time vehicle operators. Seven participants (16.7 percent) did not identify how many full-time vehicle operators were employed.

Fourteen survey respondents (33.3 percent) reported that their organizations have less than five part-time vehicle operators. Six participants (14.3 percent) reported having 5 - 15 part-time vehicle operators; five (11.9 percent) reported staffing 16 - 50; three (7.1 percent) reported having 51 - 99; one participant (2.4 percent) reported staffing 100 - 300; and one participant (2.4 percent) reported having more than 300 part-time vehicle operators. Eleven survey participants did not identify the number of part-time vehicle operators. 
Fifty percent of the survey respondents (21) reported their organizations have volunteer vehicle operators, and 16 (38.1 percent) reported they do not. Five participants (11.9 percent) did not respond to this question. The results of this survey question are shown in Figure 11.

\section{Figure 11}

Use of Volunteer Vehicle Operators

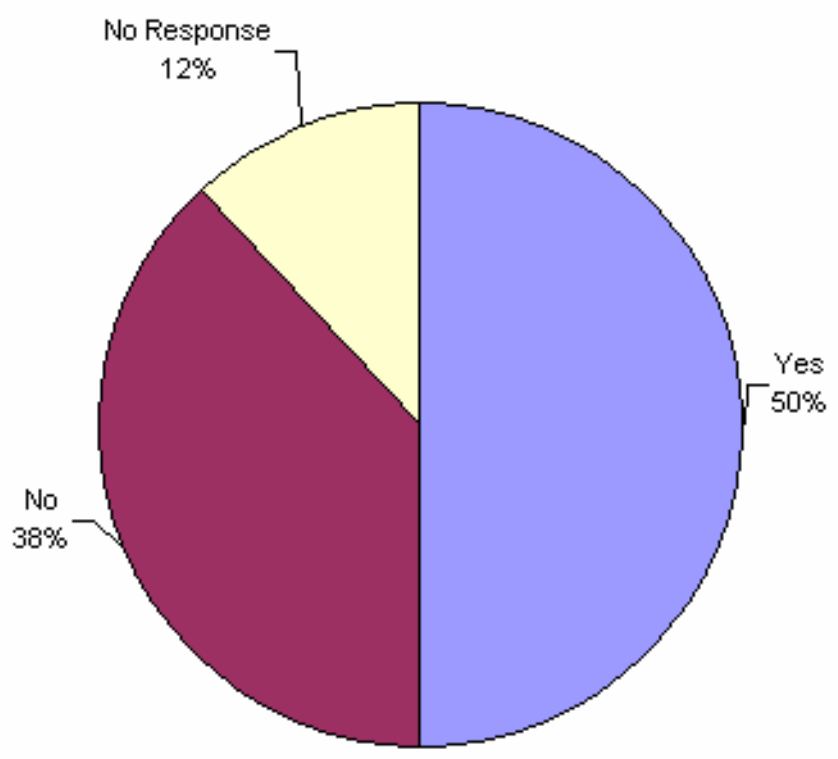

Senior Transportation Alternatives: Why Are They Important and What Makes Them Work? 
With regard to the types of training the participating organizations offer to their drivers, Figure 12 illustrates that 28 (66.7 percent) reported that they have on-site courses/training; 18 (42.9 percent) have off-site courses/training; and 11 (26.2 percent) utilize video training. Twelve respondents (28.6 percent) indicated they have other forms of training. Five survey participants (11.9 percent) did not respond to this question.

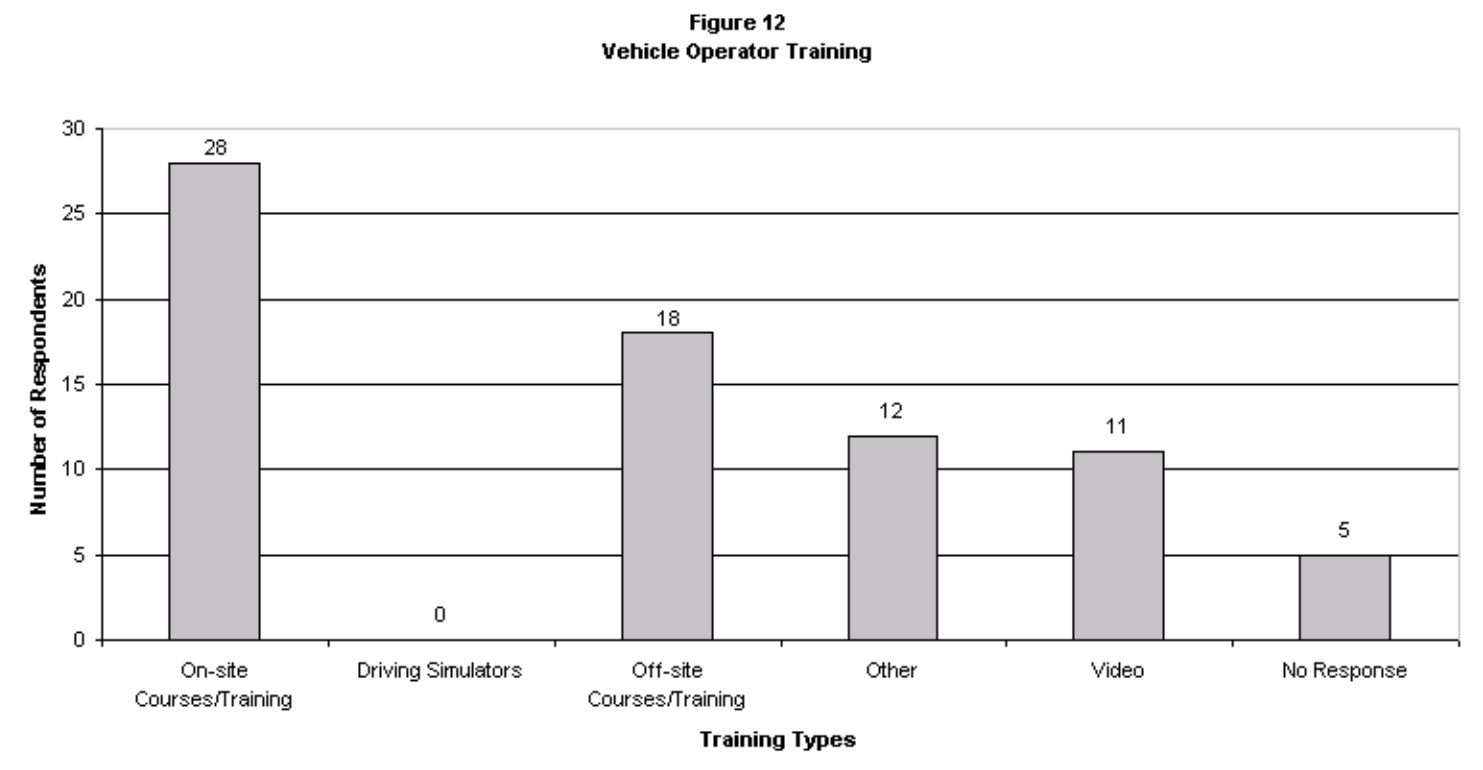




\section{Procedures}

Survey participants were asked several questions related to the procedures of their mobility services program. Reservation procedures are represented in Figure 13. According to 97.6 percent of respondents (41), clients utilize the telephone in making trip arrangements. Twenty participants (47.6 percent) claimed to have prearranged/scheduled stops; one (2.4 percent) reported that clients make on-line reservations; and 12 participants (28.6 percent) indicated their clients make in-person reservations. Four survey respondents (9.5 percent) reported other means of arranging trips, such as through social and/or medical agencies and mutual contact between seniors and volunteers.

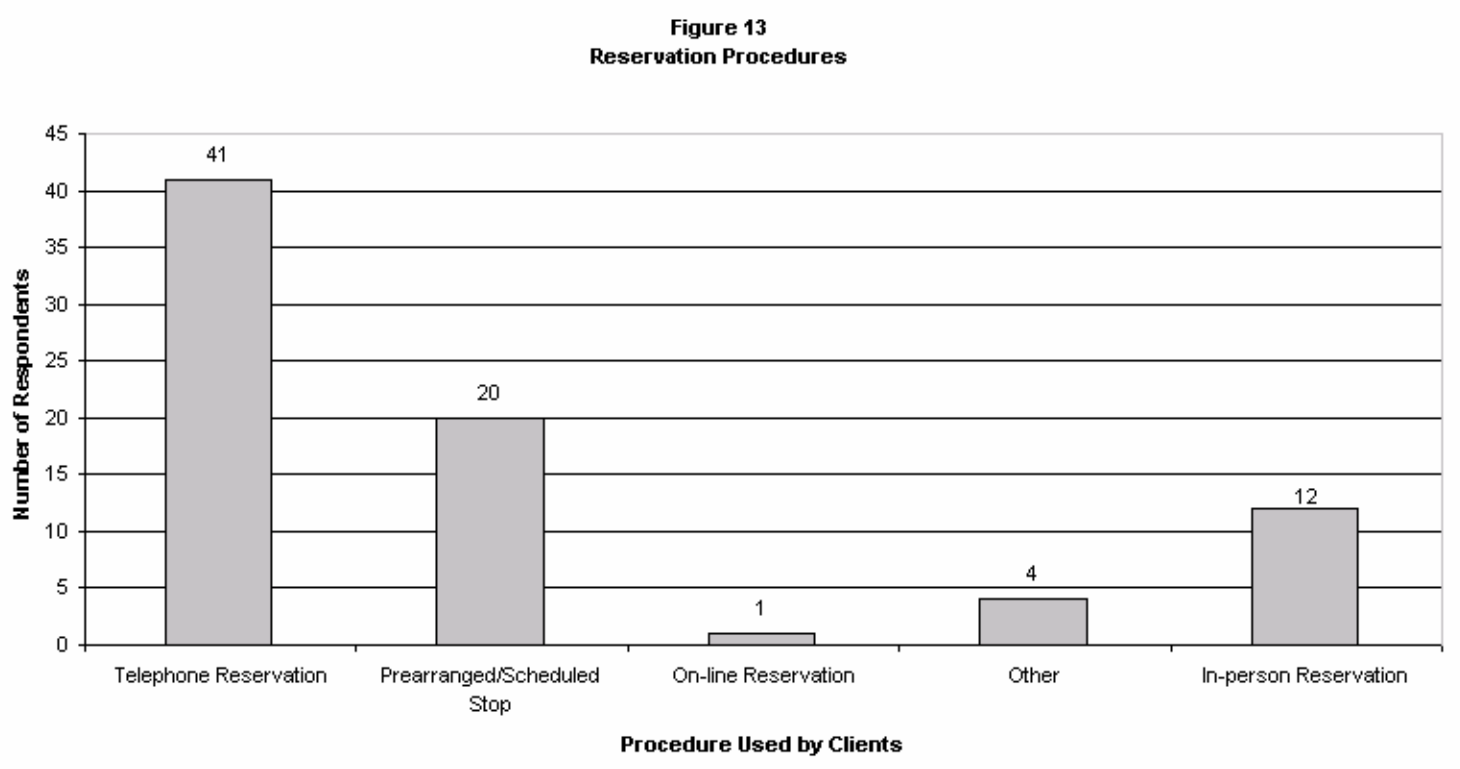

Clients utilize the participating programs' services for a variety of trip purposes, which are represented in Figure 14. The programs provide transportation for medical trips, reported by 39 survey respondents (92.9 percent); shopping trips, reported by 38 respondents (90.5 percent); recreation, reported by 28 participants (66.7 percent); and school/work purposes, reported by 18 survey participants (42.9 percent). Twenty-two respondents (52.4 percent) also indicated that their clients utilize their services for other trip purposes, some of which include personal business such as banking or grooming, volunteering, visits to nutritional sites, religious purposes, and access to legal services. 


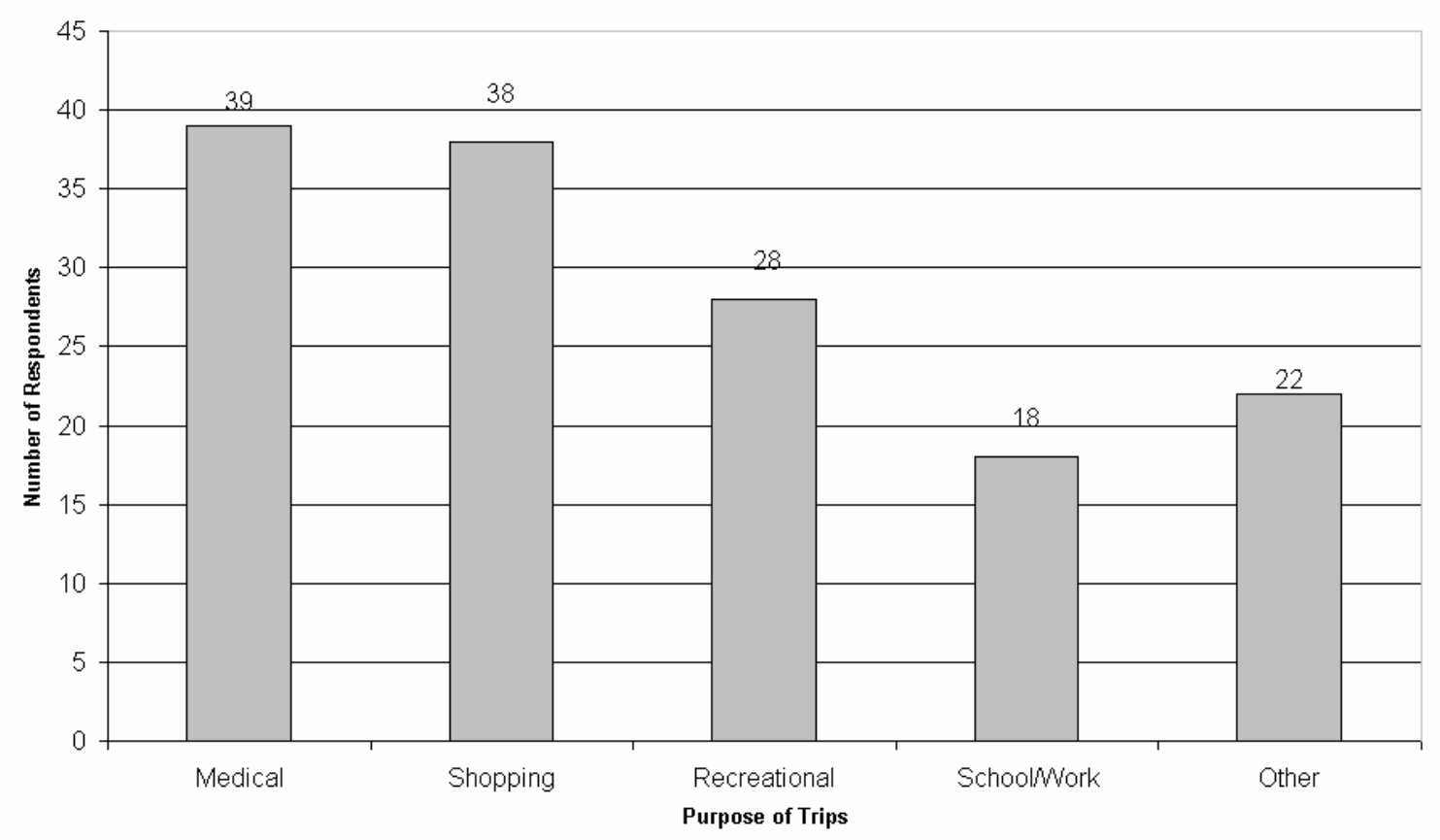

For many of the survey respondents (28, or 66.7 percent), reservations must be made one day in advance of the trip. Fourteen participants (33.3 percent) reported that their organizations require a two-day advance reservation, and 14 (33.3 percent) also reported requiring three-day advance reservations. Thirteen survey respondents (31 percent) reported that same-day reservations are accepted. Seventeen participants (40.5 percent) reported other reservation requirements, including reserved seats for specific programs and advanced notice ranging from five days up to six weeks. One participant reported that with regard to reservation timing, "the more time allotted, the better the chances." 
Figure 15 presents the variety of reasons that a client may not be able to utilize a mobility program's services. The most common reason that a trip may be denied is because it is out of the service area of the organization; this was reported to be the case by 27 survey respondents ( 64.3 percent). Ineligible passengers and no seats/vehicle available were each reported by 18 participants ( 42.9 percent). The fact that reservations were not made in advance was cited as a reason that trips are denied by 16 survey respondents (38.1 percent). Sixteen participants (38.1 percent) also reported that trips are denied because of an ineligible origin or destination. Thirteen respondents (31 percent) claimed that trips are denied for other reasons such as the unavailability of drivers, the unavailability of ADA accessible vehicles, or a trip may be denied because the client has some other means of making the trip. Five survey participants (11.9 percent) reported that trips are not denied.

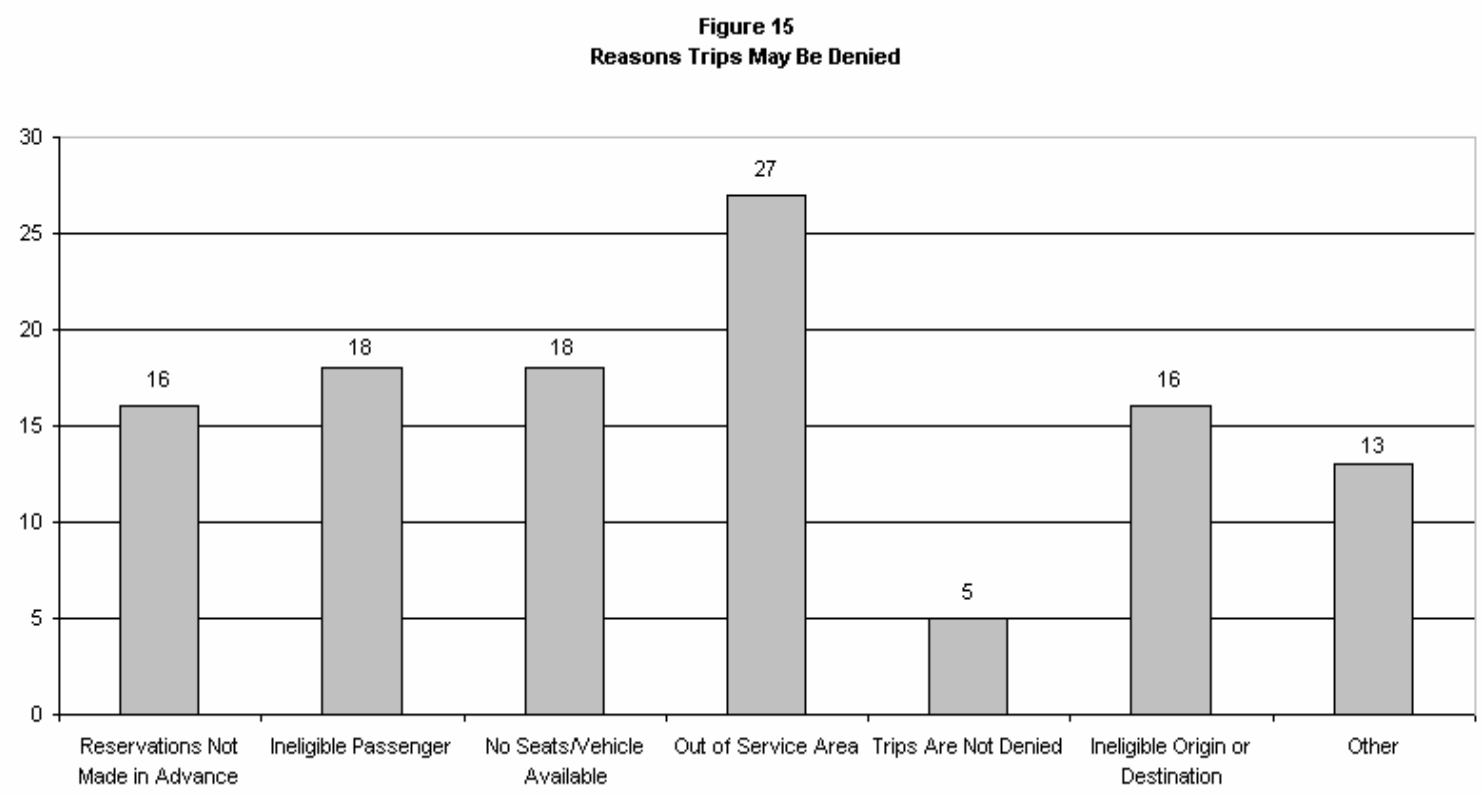

Potential clients are made aware of an organization's services through a variety of media. As illustrated in Figure 16, 30 survey respondents (71.4 percent) report that a major source of clients are generated from medical referrals; newspapers were reported by 26 participants ( 61.9 percent); telephone books were cited by 23 respondents ( 54.8 percent); and friends were reported to be a source by 41 participants (97.6 percent). Survey respondents (40, or 95.2 percent) also reported that senior centers/community centers are one means through which 
potential clients learn about available mobility services. Social agencies were reported to be a source by 38 participants ( 90.5 percent), and all of the survey respondents (42, or 100 percent) cited word of mouth as a means by which potential clients learn of the services the various programs provide. Thirteen participants (31 percent) also cited other ways in which potential clients are made aware of mobility services. Television and radio, signs on program vehicles, senior center newsletters, city publications and flyers, and a program's website are all other ways through which clients learn about the mobility services available to them.

Figure 16

How Clients Learn of Services

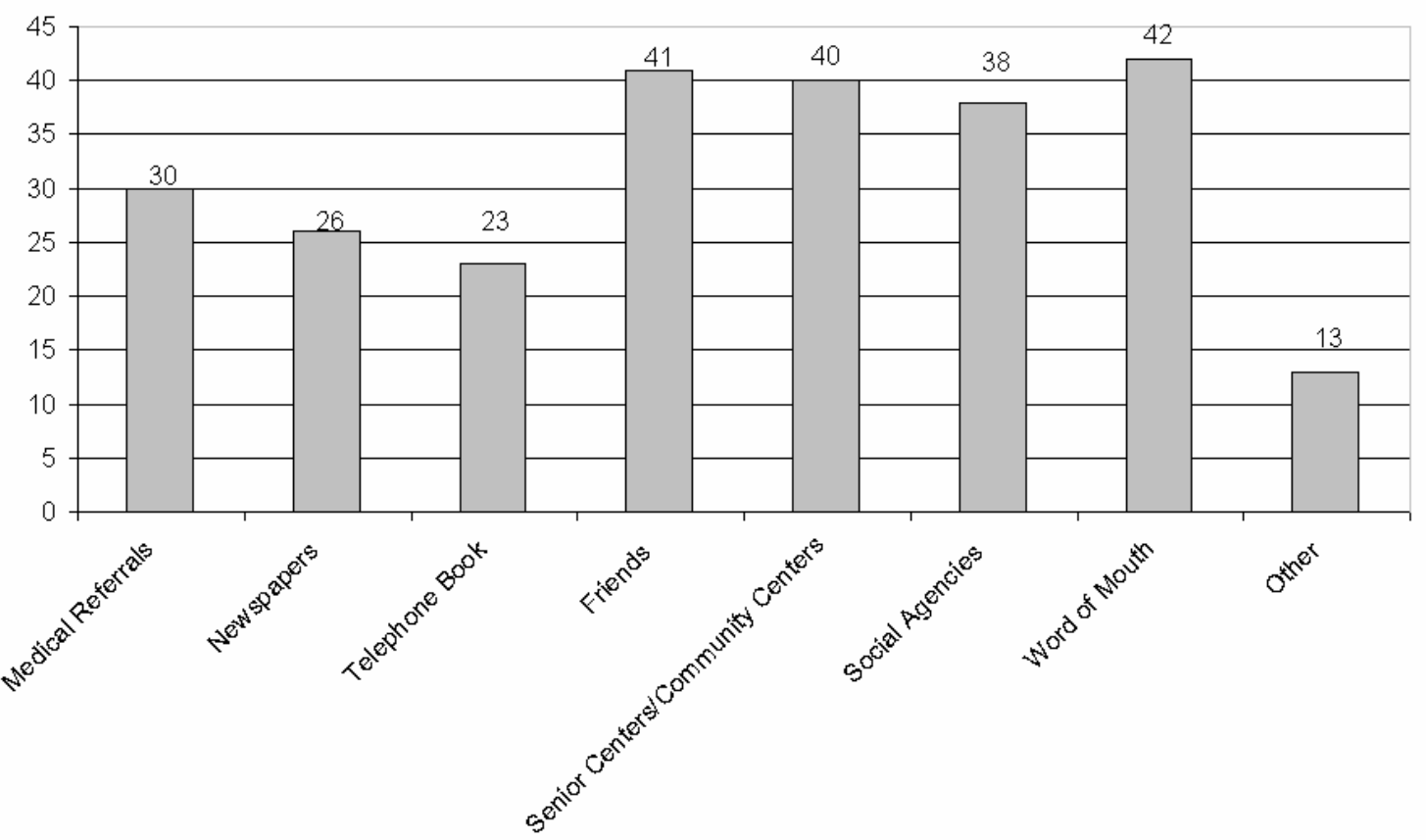

When asked to comment on which of the above means has been the most effective recruitment tool for their organization, word of mouth received the most favorable response, cited by 20 of the survey respondents (47.6 percent). As illustrated in Figure 17, the effectiveness of the strategies was classified as follows: medical referral (2, or 4.8 percent); newspapers (2, or 4.8 percent); telephone books (1, or 2.4 percent); friends (3, or 7.1 percent); senior centers/community centers (8, or 19 percent); and social agencies (8, or 19 percent). Six participants (14.3 percent) cited "other" means as the most effective tools in client recruitment. Three survey respondents (7.1 percent) noted that all 
of the above means were effective in their attempts to recruit clients. Two survey participants (4.8 percent) did not respond to this question.

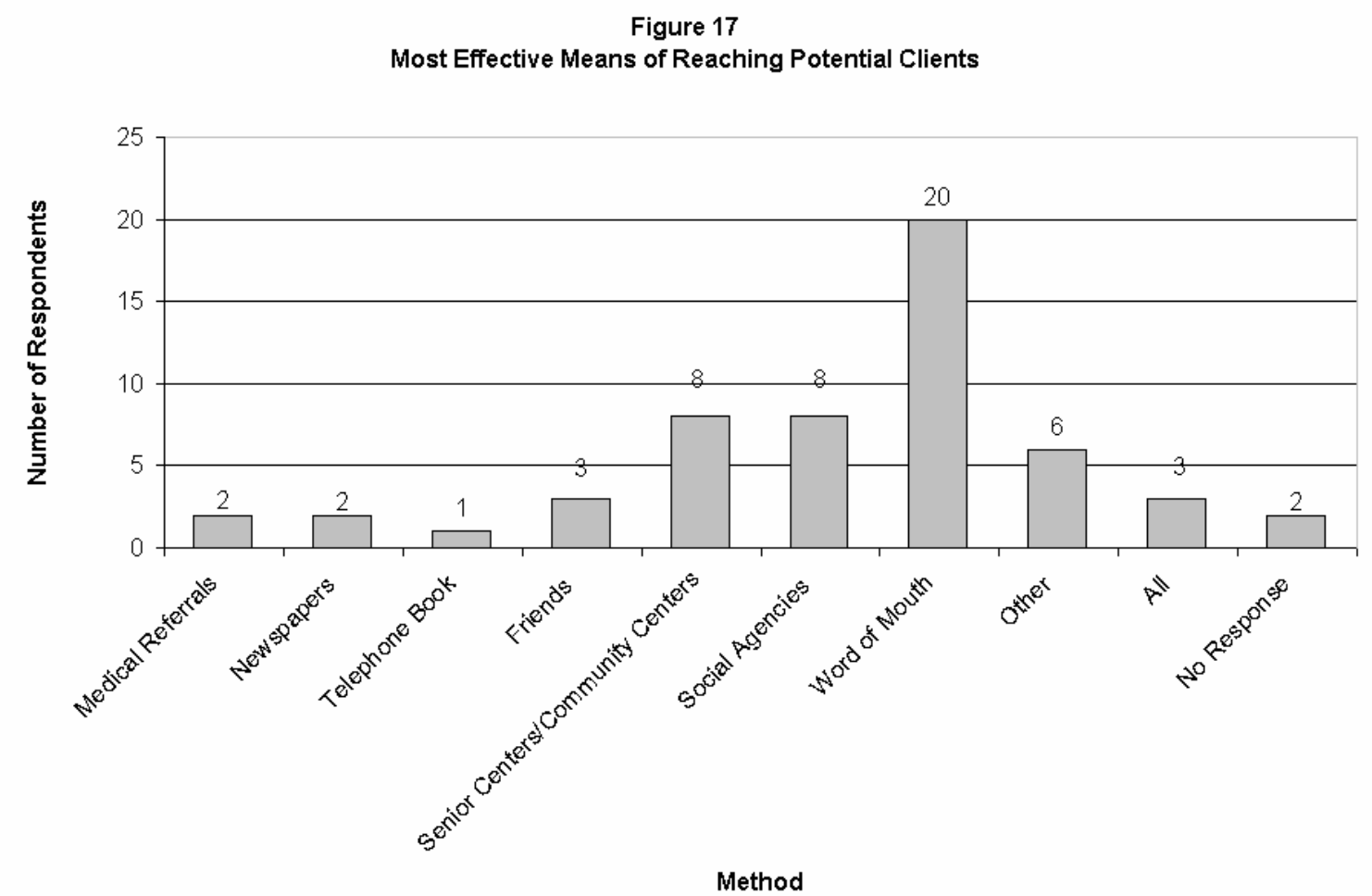

Thirty-five of the survey respondents (83.3 percent) believe their agencies have employed creative or highly successful techniques with regard to the provision of transportation services for seniors. Five participants (11.9 percent) responded negatively to this question, and two participants (4.8 percent) did not respond at all. Twenty survey respondents (47.6 percent) reported that their organizations have been recognized by a local, state, or national entity for their contributions to senior mobility. Nineteen responding organizations (45.2 percent) have not been recognized for such achievements, and three participants (7.1 percent) did not respond to this question. 


\section{Funding}

Survey participants were queried regarding their funding sources and expenditures. Nine respondents (21.4 percent) reported their organizations' 2002 total operating expenditures to be less than $\$ 50,000$. Four respondents (9.5 percent) reported their expenditures to be $\$ 50,000$ - $\$ 99,999$; four (9.5 percent) reported $\$ 100,000$ - \$149,999; nine respondents (21.4 percent) reported their expenditures to be $\$ 150,000$ - $\$ 199,999$; and thirteen survey participants (31 percent) reported their 2002 total operating expenditures to be $\$ 200,000$ or greater. Three participants (7.1 percent) did not respond to this question.

Twenty-three survey respondents (54.8 percent) reported their organizations' 2002 total capital expenditures to be less than $\$ 50,000$. One respondent $(2.4$ percent) reported his/her organization's capital expenditures to be $\$ 50,000$ $\$ 99,999$; four (9.5 percent) reported $\$ 100,000$ - $\$ 149,999$; five respondents (11.9 percent) reported their expenditures to be $\$ 150,000$ - $\$ 199,999$; and four survey participants (9.5 percent) reported their 2002 total capital expenditures to be $\$ 200,000$ or greater. Five participants (11.9 percent) did not respond to this question.

Most of the organizations receive local government funding (29, or 69 percent), while 13 (31 percent) do not, as presented in Figure 18. Local government funding comes in the form of city, county, town, and township funds and matching funds; a line item in the local government budget; municipal grants; and/or tax levies such as those on property or gasoline. The same number of organizations also receives state or federal government funding $(29$, or 69 percent), and 13 (31 percent) do not receive such funding. State and federal funding includes such sources as state Departments of Transportation; State Transit Operating Assistance (STOA) per mile and per passenger; Title III Purchase of Services (POS); Medicaid; social services and community development block grants; the Department of Human Services; Area Agencies on Aging; and the Older Americans Act block grants. 


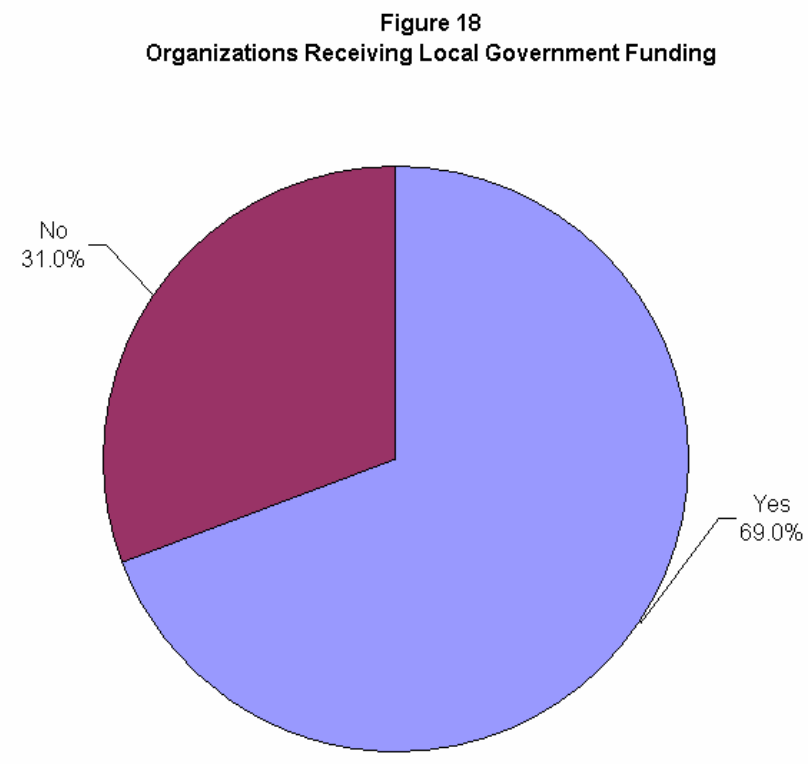

Twenty of the survey respondents (47.6 percent) reported that their organization charges clients a fare or a fee, and 22 (52.4 percent) reported that they do not. When asked to explain their fare/fee system further, 10 participants (23.8 percent) reported their organizations accept donations; eight programs (19.1 percent) charge a flat rate; two participants (4.8 percent) reported a graduated system based upon mileage; and three (7.1 percent) reported a graduated system based upon income. Four survey respondents (9.5 percent) cited other fare/fee systems. Seven participants (16.7 percent) did not respond to this section of the fare/fee question.

\section{Telephone Follow-up Interviews}

Eleven of the 42 survey respondents were consulted via telephone in order to conduct more in-depth interviews regarding several of the organizations' senior transportation services. Those selected for the follow-up interviews were chosen based upon a variety of subjective criteria, such as unique services, innovative funding sources, and volunteer coordination, among others.

During the telephone interviews, participants unanimously reported that their organizations provide a necessary and valued service to their senior citizen clientele. Interviewees stated that many of their clients have no other means of transportation, and that without the existence of such transportation programs

Senior Transportation Alternatives: Why Are They Important and What Makes Them Work? 
these older adults would be unable to meet their basic needs such as grocery shopping and doctor visits.

Most of the senior transportation services programs operate under the management of or in conjunction with a larger entity such as a city or county government, or within a volunteer/not-for-profit organization. Fewer of the organizations contacted for follow-up are independently operated or function as a collaborative of partnerships among local businesses, civic organizations, congregations, and/or other associations.

\section{Funding}

Those programs selected for follow-up interviews utilize a variety of sources to finance their services. Most receive some form of local funding, whether through grants, tax revenue, matching funds, and/or budget designation. Many of the transportation providers also benefit from state funds and/or a combination of state and federal dollars, administered through various programs such as Area Agencies on Aging, the Older Americans Act Title IIIB, Social Service Block Grants, Medicaid, and Medicare.

Interviewees are evenly divided in reference to charging clients a fare for use of the transportation service. For those who do charge fares, some have instituted a flat rate for a one-way trip within the service area. Other programs calculate the fare amount according to the distance traveled, or a fee may be assessed by the hour. Although the fares are generally considered to be nominal, clients on fixedincomes who are unable to afford the fee are typically offered discounts or waivers.

In addition to per trip or hourly charges, one of the programs included in the follow-up interviews has a \$35 annual membership fee for single clients, and a $\$ 50$ annual membership fee for couples. Memberships are also available to nonclients as a means of providing additional financial support.

In addition to, or sometimes in lieu of predetermined fares, many of the organizations accept monetary donations from riders. For many programs, donations are the only source of payment they receive from the clients for 
transportation services, and the donations contribute to the programs' funding bases. Those organizations that specifically request donations typically set a "suggested amount" for each trip, but interviewees reported that clients often donate more than the suggested amount or sometimes provide a larger donation once a month or give annually. Furthermore, fixed incomes prohibit some clients from donating on a regular basis, and some are unable to provide donations at all. For many programs, donations are essential to their operation and provide needed revenue, and although most interviewees stated that donations do defray a portion of their costs, they typically do not make a substantial financial contribution. One interviewee noted that whether from clients or through community efforts, donations are not particularly effective in offsetting costs because the public generally perceives transportation to be the devoir of government rather than a charitable entity necessitating private financial donations.

\section{Fleet}

Several of the interviewees were queried about the fleets that are used to provide senior transportation services. With regard to acquiring vehicles, most of the organizations utilize county and/or state programs through which they are able to obtain vehicles on government contracts. Some interviewees noted, however, that some government contracts limit their ability to acquire particular vehicles, such as minivans and large sedans, which would be most appropriate for their services and appreciated by the clientele.

A few of the interviewees reported obtaining fleet vehicles through donations, depending upon the organizational paradigm that guides the program. Soliciting donations has not been a common practice in building a fleet among those who were interviewed, but some programs are beginning to explore this option as a means of supplementing the procurement process. One interviewee noted in particular that donations might be one way of acquiring minivans and sedans, whereas these vehicles may not be allowed through governmental contracts. Another interviewee reported plans to expand a program through which donated vehicles are sold at auction and the value is credited to a client's account to be used to pay for future trips. This same program has also developed a brochure for local automobile dealerships to distribute to customers trading in their older 
vehicles, encouraging them instead to donate the vehicle to the senior transportation program.

Several of the organizations represented during the follow-up interviews do not formally maintain a fleet of vehicles. Those programs that utilize volunteers often make use of the volunteers' personal vehicles as well. Some programs make use of the organizations' vehicles as well as those of the volunteers, and others operate strictly using volunteer labor and vehicles.

With regard to maintenance of the fleets, those programs that acquire their own vehicles through government contracts or other means typically perform routine upkeep-fluid checks and changes, tire checks, cleaning, etc.-on-site, and contract major repairs through a local service vendor. Volunteers using their personal vehicles are typically responsible for the vehicles' maintenance and repair, in addition to upholding individual insurance coverage. The organizations also maintain an umbrella insurance policy to protect their transportation service clients, and possibly their volunteer drivers.

\section{Fixed-Route Transit Services}

A number of interviewees were queried about the availability of fixed-route transit services in their area. Respondents reported that they do encourage their clients to use fixed-route transit service, or they would if it were an available and viable means of transportation for the seniors they serve. Several noted that because fixed-route transit does not provide door-to-door service, it is not feasible for many of the older clients who have physical limitations that may prohibit them from accessing a bus stop or their final destination.

One interview participant stressed the importance of providing clients with information on the local fixed-route transit service. Older people are not always aware of the schedules and routes of their local service, and uncertainty of the trip-making process may prohibit them from using the bus. Information should be provided to them in printed and verbal formats, if necessary. Another interviewee indicated that fixed-route transit does not allow for scheduling flexibility, a transportation factor appreciated and considered to be essential by the program's clients.

Senior Transportation Alternatives: Why Are They Important and What Makes Them Work? 
Overall, programs do encourage clients to utilize fixed-route transit service, but temper that recommendation based upon the physical and logistical needs of the clients.

\section{Volunteers}

Volunteers are an integral part of many civic and social service organizations. Most of the programs chosen for follow-up interviews benefit from the use of volunteers in providing transportation for their older citizens. Members of the volunteer corps serve in a variety of capacities such as drivers, door-to-door escorts, administrative workers, reservationists, and even as companions to clients. All of the interviewees from programs with volunteer support reported that their services would not be as high quality were it not for the efforts of their volunteers. Furthermore, several programs would be nonexistent without the devotion of their volunteers, prompting one interviewee to state that volunteers are "critical; we can't do without them."

Most interviewees reported a shortage of volunteers, primarily in the sense that more are always needed. Although the programs are generally able to provide the requested trips, they admittedly could benefit from increased volunteer participation. One interviewee noted that they actually have an adequate number of volunteers, but are in need of more vehicles.

Among the organizations surveyed, senior citizens comprise much of the volunteer corps. In addition to seniors, interviewees reported a cross-section of volunteers including stay-at-home parents, younger retirees, congregation members, professionals involved in community service, and family members of clients. One interviewee also mentioned that the program has recently had several volunteers who are temporarily out of work due to lay-offs and corporate downsizing. Another organization often utilizes the labor of those who have been sentenced to community service by the courts. They are used for general property maintenance and office work, but are not used in driving senior clientele.

Recruiting volunteers is so critical to the programs that utilize them; one interviewee reported that program volunteers are recruited "any way I can get my

Senior Transportation Alternatives: Why Are They Important and What Makes Them Work? 
hands on them." Interviewees employ a variety of methods of recruitment including presentations to church congregations, civic and social groups, and volunteer organizations; notices on local cable stations; word of mouth; newspaper notices and features; flyers; and tabling at local events. One organization coaches clients to recruit their own volunteers from the people they already know-if this proves unsuccessful, they assist the client in finding a volunteer driver.

Individual agencies set their own policies regarding the criteria for volunteers. All organizations participating in the follow-up interviews require at minimum a valid driver's license, automobile insurance, and participation in an orientation or training activity. Other requirements vary by program, but may include any of the following:

- Driving record check

- Criminal background check

- Personal interviews

- Personal references

- Vehicle inspection

- Road test

Most volunteers operate on an established schedule. The organizations have generally found this to be the most functional and effective means of coordinating trips. For example, a volunteer may donate his or her time every second Monday of the month; another may volunteer every Friday. Given a set schedule, the reservationist is able to schedule clients' trips accordingly, and with more advanced notice. Some volunteers prefer to donate their time on a more erratic schedule-providing assistance when contacted by the program because there is a need for volunteers, or informing the organization when they will be available on a weekly or monthly basis. In order to maximize the volunteer corps and provide adequate service to their clients, the programs are willing to work with volunteers in determining which scheduling system best coincides with the volunteer's other commitments.

With regard to volunteer incentives, although there are no direct monetary rewards for volunteers, many of the programs do provide mileage 
reimbursement. One interviewee noted that most of the volunteer drivers return their reimbursements to the program because they want to contribute to the organization in any way they can. While altruism was cited as the primary reason that volunteers generously donate their time, they are usually acknowledged for their invaluable service with group luncheons, certificates of appreciation, awards, and similar means of recognition.

\section{$\underline{\text { Outreach }}$}

Most of the programs have some form of planned strategy for reaching potential clients, although many reported that word-of-mouth remains the most common means through which clients learn about program services.

The strategies used in recruiting volunteers are often similar to those employed to reach potential clients. In fact, these efforts are sometimes combined in order to maximize program exposure for both volunteer recruitment and client outreach. As with volunteer recruitment efforts, program staff often make presentations to church congregations, civic and social groups, and at senior centers. They place notices on local cable stations and in newspapers; have feature articles written in local publications; distribute flyers; and table at local events.

An example of how these efforts may be combined is demonstrated by one agency through a program entitled "The Road Show." Their senior transportation service program is part of a larger coordinated aging services organization. One to two times per month, supervisors from each service division visit hospitals, churches, and other groups throughout the community to present a program highlighting the various services that are available to older residents in the area. The organization uses this opportunity as both a volunteer recruitment effort and client outreach.

Other means of outreach utilized by some organizations include the production of brochures; displaying posters; distributing bookmarks; writing letters to the editor of local newspapers; producing public service announcements; and some programs issue press releases. Only one interviewee mentioned a website as a 
tool of outreach. Dependent upon the format, these efforts may be positioned in the following:

- Public libraries

- Departments of Motor Vehicles

- Senior newsletters

- Laundromats

- Local news media

- Offices of Veterans' Affairs

- Doctors' offices

- Hospitals

- Care facilities

- Senior centers

Another outreach issue facing senior transportation providers is that as the Hispanic population continues to increase, so do the number of older Hispanic Americans in need of transportation services. Some transportation programs are diversifying their outreach efforts in order to connect with this growing population. Several interviewees reported their agencies produce printed information materials in both Spanish and English. One program has advanced their Hispanic outreach efforts by instituting the staff position of Latino Outreach Coordinator. In addition there are plans to open four satellite offices in designated locations within the service area to enhance these efforts.

\section{$\underline{\text { Registration and Reservations }}$}

Once clients are aware of a program's senior transportation services, there are generally registration procedures that must be followed in order to begin scheduling trips. While the process varies by program, most of the organizations require that clients be registered with the service and make reservations, which are typically done via telephone. Some require that a client information sheet be completed, which may contain personal and medical information, as well as the name and telephone number of an emergency contact. Depending upon the organization, registration may be completed and reservations may be made through a volunteer or a paid staff member, and some programs utilize both for these services. 
Requirements for registration vary by organization, including some that reported no predetermined eligibility requirements and others that may have geographic restrictions, minimum age restrictions, ambulatory standards, and/or income restrictions.

Clients are generally able to arrange for transportation once they have registered with the service. Notice requirements range from 24 hours up to one week in advance. Interviewees reported that they are better able to accommodate clients when given as much advance notice as is possible, but always make every attempt to oblige client requests.

\section{Program Evaluation}

As with any service provider, senior transportation programs can benefit greatly from periodic program evaluations with their clients. Most of the interviewees reported that their organizations have done some type of formal evaluation; those who have not, acknowledged that doing so would assist in fulfilling program goals and enhancing responsiveness to client needs. One interviewee stated that customer satisfaction should be monitored so that organizations can "continually update and change to meet needs better."

Representatives participating in the telephone interviews from organizations that have performed program evaluations report receiving overwhelming positive response and appreciation for their services. Several interviewees noted that drivers receive much of the praise from clients, most often for being friendly, helpful, patient, and making riders feel welcome in the vehicle. One interviewee asserted that the "personality of drivers and dispatchers is key." Another interview participant noted that drivers often serve the well being of clients beyond their duties of transportation. Because the drivers see the clients on a regular basis and come to know them personally, drivers may be able to alert family members or caregivers to problems such as declining mobility or similar physical or personal care issues. The senior clientele feel comforted by the knowledge that others are concerned for their welfare. 
Evaluation procedures vary by agency. While some may survey riders every quarter, others may perform surveys on an annual basis. Some attendees reported that their organization had completed some form of evaluation in the past, but it had either been so long they were unable to recall when it was done, or evaluations were done prior to the interviewee's involvement with the organization. One interview participant reported that customer satisfaction surveys have been done in the past, and that impact surveys are planned for the future to determine how effective the program has been.

Although not all of the participating organizations have performed a formal evaluation, all receive feedback from clients in the form of letters, cards, and inperson reaction. Anecdotal responses to the organizations and services were also reported to be extremely positive. Several interviewees reported receiving or hearing the comment, "I don't know what I would do without you" in relation to their transportation services.

While the majority of feedback is reported to be positive, several interviewees admitted that mistakes can and do sometimes happen, possibly resulting in a client not being transported as promised. Acknowledgement, assumption of responsibility, and respect for the client are of the utmost importance in these situations. Agencies typically apologize to the client, and they may offer some sort of conciliatory token and/or a credit towards future transportation services. One interviewee explained that when program staff "really mess up," the client receives a personal visit, including flowers and an apology.

In addition to the importance of meeting healthcare needs, evaluations and unsolicited client feedback have provided program staffers with an understanding of the value that senior clientele place upon non-medical transportation services. Most particularly, interviewees asserted that such trips contribute greatly to their senior clients' overall quality of life. Clients who use bus or van transportation have reported they enjoy the socialization of riding together and that they generally have a "fun time" onboard the vehicle. Those on group shopping trips often share product recommendations and assist each other while in the store. Some clients have told program staff that having transportation gives them something to look forward to, and many have stated they would not otherwise

Senior Transportation Alternatives: Why Are They Important and What Makes Them Work? 
leave their homes. One interviewee stated that transportation is crucial for seniors, and that its "social value is as important as mobility."

Interview Participant Recommendations

Participants in telephone follow-up interviews were queried regarding their lessons learned and recommendations for others in providing senior transportation services. The most common advice from interviewees is that relationships should be established with as many partners in the community as is possible because alliances are critical to the success of a senior transportation program. Several interviewees caution start-up programs not to become an "island," and that doing so would be a detriment to service programs and their clients. Interviewees further recommend that programs should continually seek opportunities for new partnerships, expanding the network of collaboration. One interviewee reported that the program is able to provide integrated services for seniors because it has minimized the necessity for revenue by partnering with more than 200 organizations in the county. Another interviewee contended that many professionals, congregations, civic groups, institutions, and organizations in the community are willing to help, and that one should engage all the "major players" in aging services. In creating and maintaining community partnerships, one interviewee asserts that the sharing of information, ideas, and references is crucial because this maximizes the opportunities for partnering.

Because transportation services can be expensive to provide, one interviewee recommends that good business sense be used in program design and in all subsequent decisions. Another interviewee suggests securing underwriting and being assured of a sound financial ground before establishing services. A third interview participant asserts the need for an annual fundraiser, noting that the nature of senior services and of local events typically produces "warm and fuzzy" feelings, which should translate into community support for a senior transportation program.

Based upon their experiences in providing a variety of transportation options for older people, interview participants also provided the following suggestions for implementing and/or maintaining a successful senior transportation services program:

Senior Transportation Alternatives: Why Are They Important and What Makes Them Work? 
- Do not count on anything.

- Do not make promises you cannot keep; until you have something in place, keep it quiet.

- Be sure to use good information management technology.

- Do not give the transportation away; that is a common mistake.

- Start small with only one or two days per week.

- Have restrictions for age, purpose, and time.

- Employees need to be patient and caring with clients.

- Be very aware of safety from the beginning.

- Do a lot of brainstorming.

- Know your community.

- Use the specialties of each person on the board.

- Just have fun with it.

According to one interviewee, it is "way past time to sit up and notice the changes in demographics; we are in a national crisis," referring to the growing population of older Americans and the need to plan for senior transportation services in the future. The senior transportation service providers responding to the survey in this study are attempting to meet the current challenges of senior transportation, while also planning for the future needs of an aging population. 
Senior Transportation Alternatives: Why Are They Important and What Makes Them Work?

Page 66 


\section{Chapter Four Successful Strategies in Senior Transportation Services}

This chapter identifies those creative and effective techniques used by agencies providing transportation alternatives to seniors. The hope is that those communities that have a void in the area of senior transportation services, or those that are looking to improve their existing services will use this resource to communicate with agencies that have successfully done what these communities want to do.

These successful strategies have been categorized by issues of importance, based upon both the focus group discussions and the literature review. These issues include client outreach; adequate funding; costs to participants; effective use of volunteers; convenience to seniors; and the preservation of dignity and independence.

\section{Client Outreach}

As noted in the description of the focus group discussions, many of the senior participants claimed they are not familiar with the transportation alternatives available to them. Many stated they are uncertain as to the source of such information, and would not know where to search should they require transportation services. Through the survey, NCTR asked the senior transportation providers to identify the techniques they use to educate seniors and to build the client base for their alternative transportation services. As noted in Chapter Three (Figure 16), many of the participating agencies receive new clients through medical referrals, media coverage, telephone books, friends or word of mouth, senior centers, and social agencies. Follow-up interviews with some of the survey participants suggest that, for a few agencies, continuous outreach has not been a priority as they already have all the clients that they can handle. From the client's point of view, however, there is often a serious void in the area of communicating alternatives to seniors. Some participants in the follow-up interview process noted that, while they may have more than enough clientele, they are aware that there are many more seniors in their communities in need of transportation services. As a result, some of the senior transportation

Senior Transportation Alternatives: Why Are They Important and What Makes Them Work? 
providers surveyed and interviewed have implemented creative outreach techniques that have been effective tools for marketing services and attracting clients.

\section{The Road Show}

- Cecil County Department of Aging Transportation Program Elkton, Maryland

The Cecil County Department of Aging operates its Transportation Program within a service area population greater than 90,000 persons, of which more than 12,000 are senior citizens. Full-time staff and approximately 5 volunteers support the transportation services program, which serves a 348 square mile area. The program provides medical, shopping, recreational, school/work, and special event transportation to older residents primarily, but services are available to the general public as well.

For little more than a year the Department of Aging has been presenting the "Road Show," once or twice each month. The Road Show is a traveling presentation during which supervisors from all divisions within the Department of Aging provide information about the programs the agency sponsors and how seniors can avail themselves of the various services. The Road Show has been presented to church groups, senior groups, service organizations, domestic violence groups, social services, adult education groups, hospices, hospitals, and AARP groups.

The presentation lasts little more than one hour, during which time the supervisors explain the Department's programs and answer questions that audience members may have. According to a program representative, this method of outreach has been very successful, and in a short time has resulted in the recruitment of 10 to 20 new clients. Audiences range between six and 50 people, who attend either because they requested the Road Show, or because the Department of Aging asked to make the Road Show presentation. Currently, the supervisors take individual unit and Cecil County Department of Aging brochures to distribute during the Road Show. They are also in the process of developing a new brochure for future shows. 


\section{Marketing /Outreach Positions}

- The Senior Connection

Silver Spring, Maryland

The Senior Connection provides transportation and other support services to older residents in lower Montgomery County, Maryland. The service area is 135 square miles, and the service area population is approximately 130,000 persons. The program operates as a non-profit organization, with 60 part-time volunteer drivers.

According to Census 2000 data, Latinos/Hispanics account for almost 12 percent of the total population in all of Montgomery County, and program staff report this population to be the fastest growing segment in the county. The Senior Connection has recently undertaken new initiatives regarding outreach to the seniors in this community, including the establishment of a Latino-Hispanic Outreach Coordinator. Because two Latino-Hispanic social workers were already housed in the offices of the Senior Connection, a program representative notes that it was most logical to begin outreach to seniors in this community. The Latino-Hispanic Outreach Coordinator has established contact with a number of congregations in the service area, and the Coordinator and program staff have met or have appointments to meet with the congregations in order to present what services the Senior Connection can provide their senior members.

The program also plans to open four satellite offices in Housing Opportunities Commission (HOC) areas. The HOC operates as a public housing agency, a housing finance agency, and a housing developer. Its mission is to provide affordable housing and supportive services that enhance the lives of low- and moderate-income families and individuals throughout Montgomery County. The HOC administers several housing programs specifically for senior citizens in the County. Thus far, the Senior Connection has trained 21 student volunteers to assist in one of the new satellite offices housed at a HOC senior resident facility with more than 35 percent Latino-Hispanic residents. 
- York County Community Action Corporation (YCCAC) Sanford, Maine

The YCCAC operates several non-profit transportation programs within a 1,000 square mile service area in York County, serving a population of approximately 187,000 persons. Slightly more than 25,000 residents of York County are age 65 years and older. The agency is supported both by full-time staff and 85 volunteer drivers who provide personal vehicle transportation to those clients for whom YCCAC vehicles are not accessible, whether due to physical or scheduling constraints.

The YCCAC has recently established the position of Marketing Director for the agency. The new Marketing Director is responsible for developing brochures and other information pieces for the agency and its various programs; compiling the YCCAC newsletter; organizing community events, such as the Fall Neighborhood Cookout; and coordinating grant applications for the various programs at YCCAC.

According to the responding program representative, this new position was created because the YCCAC was "the best kept secret in York County" and the fact that the organization did "not have a single voice or public image." Although the YCCAC does not currently determine how new clients learn about the services, the brochures are quite popular and require frequent replenishment. Furthermore, the agency has increased its visibility within the local community.

\section{Television/Newsprint Media}

While standard exposure using television and newsprint media can be quite expensive, some senior transportation programs have devised innovative and inexpensive ways of utilizing these media in their client outreach efforts.

- Cecil County Department of Aging Transportation Program Elkton, Maryland

The Cecil County Department of Aging Transportation Program, highlighted previously for its "Road Show," will use a "weather crawl" to advertise its services 
through the local cable television provider. Beginning in January 2004, an announcement describing the Transportation Program will run under the local forecast on the Weather Channel. The fee for the weather crawl is 50 dollars per week and it will run once every two hours, with up to 270 letters allowed per announcement. This method was selected for client outreach over a standard television commercial because of the relatively low cost of the weather crawl. No discount is provided to the Cecil County Department of Aging Transportation Program as a public service agency; however, television is further utilized as an outreach medium by issuing public services announcements, which are aired at no charge to the Department.

- Independent Transportation Network (ITN) Westbrook, Maine

ITN is a nonprofit organization that began in 1995, providing transportation services to seniors and those with visual impairments. Its mission is to provide "dignified, economically sustainable transportation to seniors." Volunteers use their personal vehicles to provide door-to-door transportation services within a 15-mile radius of Portland, Maine, to a service area population of 225,000 persons. ITN was modeled after private automobile ownership, and hence provides service to clients for any trip purpose, twenty-four hours each day. Clients are charged fares per hour or per mile.

ITN utilizes television and newsprint media by issuing public service announcements (PSAs) and press releases when there is a specific event or however often it seems appropriate, in accordance with the various media outlets' guidelines for submission and updates. The PSAs and press releases allow for no-cost means of client and volunteer outreach, utilizing typically expensive media, while also increasing ITN's visibility within the community.

\section{Written Information Materials}

Many senior transportation programs produce written information materials such as flyers, posters, and brochures in-house, often saving money while utilizing the creative skills of staff and volunteers. Some organizations have expanded upon 
the basics to include innovative ways of reaching potential clients and informing them of the services available to older adults in their communities.

- Coordinated Services for the Elderly Hilo, Hawaii

Coordinated Services for the Elderly, part of Hawaii County's Office of Aging Benefits Counseling, provides information and assistance, outreach, transportation, chore, and other support services to older residents of Hawaii County. Transportation services are provided at no charge to seniors within a service area of 4,028 square miles. The total population of Hawaii County is approximately 40,000 persons, and almost 14 percent of residents are age 65 years and older.

The agency has developed "Information and Assistance" program publications that provide the area's elder population with telephone numbers and contact information for senior centers, social agencies, and other senior support services. Such an inclusive publication addresses the concerns expressed by some of the study's focus group participants that information on the variety of senior services is neither adequately identified nor easily located. Furthermore, focus group participants expressed the general desire to have such information compiled into a single source. The "Information and Assistance" publications created by Coordinated Services for the Elderly address that specific concern.

- Partnership to Preserve Independent Living for Seniors and Persons with Disabilities-Transportation Reimbursement and Information Program (TRIP)

Riverside, California

TRIP is one service program of the non-profit Partnership to Preserve Independent Living for Seniors and Persons with Disabilities. The program provides information to seniors and persons with disabilities on the availability of transportation, including brochures and schedules for all specialized transit services. TRIP provides mileage reimbursements to volunteer drivers who transport senior and disabled residents who are unable to use the County's other

Senior Transportation Alternatives: Why Are They Important and What Makes Them Work? 
transportation services. The client receives the reimbursements from the County, and then distributes the funds to his/her volunteer driver/s. Qualifications for assistance are determined through an application procedure administered by the Partnership to Preserve Independent Living for Seniors and Persons with Disabilities. The program has a service area of 7,200 square miles. The service area population is 1.5 million, of whom more than 200,000 persons are age 65 and older.

TRIP produces bookmarks that highlight its transportation services, and they are distributed in public libraries, laundromats, Offices of Veterans Affairs, senior centers, legal services offices, and other similar locations that seniors might frequent. The bookmarks are printed in English on one side and Spanish on the other. The English version of the bookmark is presented in Figure 19. During the Census 2000, 36 percent of Riverside County's population classified themselves as Hispanic or Latino, indicating the need for bookmarks to be printed in both English and Spanish.

Figure 19: TRIP Promotional Bookmark (English Version).

\section{If You Need.....}

VOLUNTEER ASSISTED TRANSPORTATION?
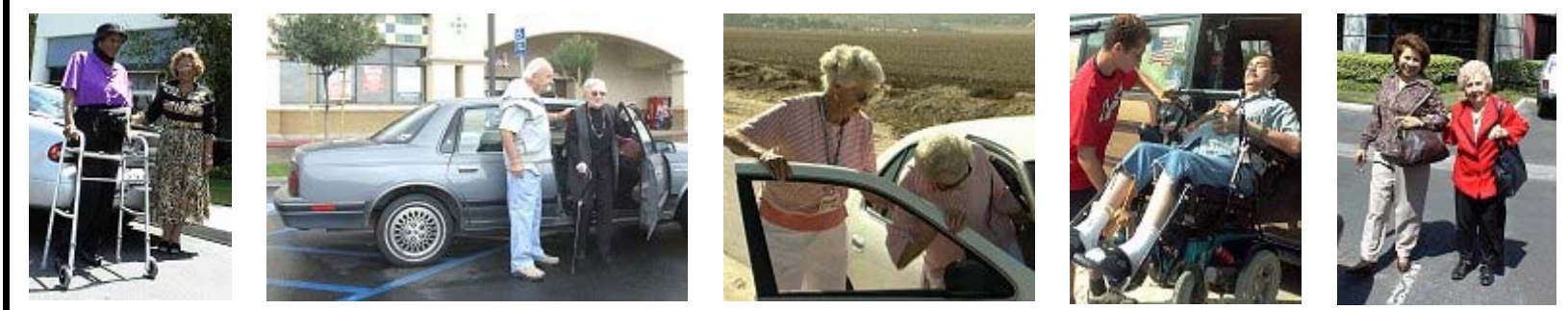

Call 1-800-510-2020 to apply for "TRIP".

The bookmarks have been in demand, and calls to HelpLink, a toll-free telephone information line for the Riverside County Office on Aging, have increased. While this increase has not yet been quantified, the current number of applications that have been submitted for the bimonthly client eligibility review is higher than average. Furthermore, as a result of the bookmarks, TRIP has recently gained a local church committee to serve as a new volunteer driver corps unit for the program. 
The Partnership also publishes a quarterly magazine, Meeting the Challenges, which contains articles on a variety of subjects, including transportation and the TRIP, that are of interest to senior citizens as well as persons with disabilities. The magazine contains no commercial advertising and is free of charge to older adults and those with disabilities who reside in Riverside County. Others may receive an annual subscription to the magazine for a suggested donation of ten dollars or more. The magazine currently has 30,000 subscribers.

- York County Community Action Corporation (YCCAC) Sanford, Maine

The YCCAC has created posters specifically for each of the 29 towns in its service area. The posters are intended to educate senior and low-income residents without transportation about the services available to them for shopping purposes. They have been designed to explain how simple it is to use the transportation services offered by the YCCAC, the days and times the bus is in the particular town, where it transports riders, and the telephone number to call for further information.

\section{Technological Tools}

- Partnership to Preserve Independent Living for Seniors and Persons with Disabilities-Transportation Reimbursement and Information Program (TRIP)

Riverside, California

The Vital Connections website (http://www.vitalco.net) is another service program of the Partnership to Preserve Independent Living for Seniors and Persons with Disabilities. The website serves as an internet portal for a variety of senior services in the Riverside area, and receives 600 to 1,000 hits per month. Although the site links visitors to information about TRIP and the Partnership's website (http://www.livingpartnership.orgh), a program representative estimates that the Living Partnership website receives considerably less hits each month. 
TRIP has also produced a video explaining its transportation and reimbursement program. Approximately 150 of the videos have been sent to other entities that serve TRIP's targeted constituency within Riverside County including organizations, agencies, service providers, and some religious organizations. The video has been a useful tool in explaining the workings of the program, recruiting volunteer drivers, and through members of the driving corps, seniors in need of TRIP services have been identified and/or referred to the program.

\section{Costs to Participants}

Participants in the focus group discussions were of diverse opinions regarding what qualifies as affordable alternative transportation. While some expressed the opinion that taxis are an affordable option as compared to the costs of maintaining a personal vehicle, several other participants noted that while taxis are a sufficient means of travel, they are too expensive to be a sustainable option for many seniors. Such a division was typically based upon income-participants in the focus group with the highest average annual household income generally expressed the opinion that market rate taxis are an affordable option. Senior transportation providers are certainly aware of the economic diversity among older adults and the situation of those living on fixed incomes. Many organizations have developed programs that address not only the necessity of adequate transportation, but affordable alternatives as well.

Many of the programs surveyed and interviewed function on a donation-based fare collection system. While there may be a "suggested donation" amount, typically ranging from $\$ 1.00$ to $\$ 5.00$ per trip, other programs simply request a donation but do not suggest a particular amount. Although some seniors may not be financially able to provide a donation, trips are not denied in such cases. Clients are permitted to donate an amount of their choosing, and several interviewees reported that clients are so grateful for the services that they often donate more than the suggested amount. Because donations do not typically provide a major source of revenue for the programs, there is often a "balance" between high and minimal or zero donations. 
Some of the senior transportation providers that do charge fees for their services have implemented programs that address the issue of fixed-incomes and the fact that not all clients may be able to pay for the full cost of their trip.

\section{Community Roads Scholarship Program \\ - Independent Transportation Network (ITN) Westbrook, Maine}

ITN typically charges clients for its services on a mileage or hourly basis, the costs of which are deducted from prepaid accounts. The organization has recently developed the Community Roads Scholar Program for low-income seniors with a demonstrated financial difficulty in paying for rides. The scholarship fund provides 50 dollars per person, per year. Once scholarship funds have been depleted, the scholarships are suspended until more funds are donated. ITN reports that thus far, the organization has been able to serve every qualified senior who has applied for the program. Qualified seniors are those who have ever been declared to be low income by any social or governmental agency. Those who have not been "officially" classified as low income at any time in the past must complete a form divulging their income and submit it to ITN in order to become qualified for the Community Roads Scholar Program.

ITN is also expanding its car donation program that allows community members to donate their vehicles to ITN to be used in providing transportation services, while receiving a credit to designated accounts. ITN will also sell a donated vehicle at auction, crediting the cash value to a member's account for current or future transportation services, or for use in the organization's fleet. This program has been particularly successful in supporting ITN, and staff have "lost count" of the number of vehicles turned in through this means.

\section{Graduated Fee Program}

- Catholic Charities Elderly Services (CCES) Honolulu, Hawaii

The CCES Transportation Services Program provides transportation to seniors residing anywhere on the island of Oahu, a service area of 593 square miles. The program's service area population is approximately 142,120 persons. The 
nonprofit organization provides door-to-door and curb-to-curb transportation for those age 60 years and older for medical, shopping, recreational, and group dining purposes. CCES also provides support services for older Oahu residents.

CCES clients pay a graduated fee based upon their income if it is more than 151 percent above the poverty level. The graduated fee is five, 10, or 15 dollars per one-way trip. Clients are required to complete a Senior Assistance Management System (SAMS) form, providing information regarding their income, Activities of Daily Living (ADL), and Instrumental Activities of Daily Living (IADL). If a client has two ADLs or two IADLs he/she qualifies for a seat funded by the Hawaii State Contract, and pays a graduated fare amount if his/her income is more than 151 percent above the poverty level. If a client does not have two ADLs or two IADLs he/she qualifies only for a federal contract seat, and pays nothing regardless of income. CCES reports that currently 95 percent of their clients pay no fee for their transportation services.

- Waukesha County Department of Senior Services Waukesha, Wisconsin

The Waukesha County Department of Senior Services operates within a population of 360,000 in Waukesha County, Wisconsin, an area of 576 square miles. The agency is a local-government operated entity that contracts with local transportation providers in return for county subsidies. The Department of Senior Services sponsors subsidized transportation services for non/limited-driving persons age 65 years and older and for persons with disabilities. When approved for transportation services, applicants receive a discounted fare.

Transportation services vary depending on the community in which county residents live, and whether the individual is ambulatory or non-ambulatory. Fares for one-way trips are subsidized depending on the person's ability to pay, the distance traveled, the transportation program used, and the subsidy rate established by the Department of Senior Services.

Costs for the Shared-Fare Taxi Program vary by taxi provider. Clients pay a minimum of $\$ 3.25$ toward the cost of each one-way trip. If the trip cost is more than $\$ 9.00$, clients pay the $\$ 3.25$ plus any amount over $\$ 9.00$. 
With regard to the agency's van service, known as the RideLine Program, fares are determined by a client's ability to pay. This calculation is based upon information the client provides on the Fare Determination Form, which is completed at the time of application. This form is presented in the appendices.

Fares for the RideLine Program range as follows:

- \$3.25-\$7.25: one-way trip within same community

- $\$ 4.25-\$ 9.75$ : one-way trip, origin and destination is from one community to another;

- \$6.75-\$16.25: one-way trip, out of county when preauthorized for medical appointments.

Should a client choose not to provide income and other financial data, the client will be charged the maximum fares.

The Waukesha County Department of Senior Services also provides a Shuttle Service Program, but there is no application or certification process required to use the shuttle services.

- Hillsborough County Sunshine Line Tampa, Florida

The Sunshine Line is a local-government operated program that serves a population of more than one million in Hillsborough County, an area of more than 1,000 square miles. The program provides door-to-door transportation and bus passes for senior, low-income, and disabled persons who do not have or cannot afford their own transportation. The transportation services primarily transport seniors to medical facilities, Aging Services daycare, and Senior Citizens Nutrition and Activity Program (SCNAP) sites.

Although medical trips are given priority, non-medical trips are provided on a space-available basis. Fees are charged for some trips, and the amount of the fee charged is based upon client eligibility and funding source rules. The costs to clients range from zero to five dollars, depending upon their income. Clients are asked to call and be screened by Sunshine Line in order to determine their fare cost, based upon the different funding sources. 


\section{Funding}

The avenues by which the senior transportation programs surveyed and interviewed are funded vary along the spectrum between no support from local, state, or federal government sources and full support from such sources. Often the decision to pursue government funding depends on the type and level of services provided and organization types. Highlighted below are senior transportation programs that have elected to pursue funding at various levels along the spectrum mentioned above.

\section{Receives Financial Support from Government Sources}

- Shopper Hopper

Boynton Beach, Florida

The City of Boynton Beach, Florida successfully levied local option gas tax for the enhancement of transportation services and infrastructure. One specific use of funds generated from the local option gas tax is to support the Shopper Hopper Program, which transports passengers from their homes or general pickup areas to area shopping centers and grocery stores. While the service is available for any resident of Boynton Beach, between 75-100 percent of the passengers are over the age of 65 .

The local option gas tax generates approximately $\$ 170,000$ annually for the Shopper Hopper Program and another service operated by the County that transports seniors to the city's Senior Citizen Center. In 2003, the total expenditures budgeted for these programs were $\$ 243,000$. The remaining funds used to cover expenditures are generated from fares and bus advertising.

- City of Huntington Beach Senior Mobility Program Huntington Beach, California

The City of Huntington Beach, California is one of several municipalities participating in the Orange County Transportation Authority (OCTA) Senior Mobility Program. The Senior Mobility Program was created to fill the gap between local fixed route transit and ADA paratransit services by providing additional local transportation alternatives for seniors in the County. 
The Senior Mobility Program in Huntington Beach provides transportation to medical appointments, grocery shopping, senior centers, special events, and the adult day center. OCTA provides up to 80 percent of the funding for the Senior Mobility Program; while the City of Huntington Beach and state block grant funds supply the remainder. In addition, OCTA provides used vehicles and technical support to the agencies that participate in the Senior Mobility Program.

\section{Receives No Financial Support from Government Sources \\ - The Shepherd's Center of Greater Kalamazoo Kalamazoo, Michigan}

The Escort Transportation Program at the Shepherd's Center of Greater Kalamazoo provides one-on-one escorted transportation services for seniors age 60 years and older in Kalamazoo County. The County is an area of 580 square miles, with a population of 238,000 persons, almost 60,000 of whom are seniors age 62 years and older. The program began in 1991, and provides transportation for medical appointments and other health-related needs Monday through Thursday. On Wednesdays and Fridays the program serves the non-medical transportation needs of its clients.

The Shepherd's Center of Greater Kalamazoo is one local center affiliated with the Shepherd's Centers of America (SCA), an interfaith, not-for-profit umbrella organization that coordinates nearly 100 independent Shepherd's Centers throughout the United States. According to the national organization's website (http://www.shepherdcenters.orgh), "the primary purpose of a Shepherd's Center is to enrich the later years with opportunities for service to others, selfexpression, meaningful work, and close friendships. An equally important goal is to help older adults remain independent in their own living situation as long as they choose."

With regard to funding, the Robert Wood Johnson Foundation awarded the Shepherd's Center of Greater Kalamazoo a Faith in Action operating grant to enhance their Escort Transportation program to include some errands and nonmedical appointments. In addition, the organization has received an operating grant from a local foundation to assist in the provision of senior services.

Senior Transportation Alternatives: Why Are They Important and What Makes Them Work? 
Donations from local organizations, churches, and individuals provide the remainder of the Center's operating budget.

At this time the Shepherd's Center of Greater Kalamazoo has no plans to pursue any level of government grant funding. There is some concern that securing government grants could have an effect on the mission of the local Shepherd's Center, and that of its parent organization, SCA.

- Jewish Family Service-Senior Transportation San Diego, CA

The Jewish Family Service Senior Transportation program provides transportation to medical and dental appointments for seniors who are members of the College Avenue Senior Center. The service may also be used for group shopping trips. The transportation program receives no local, state, or federal government source funding; however, it maintains its service through fares and contributions from private sources, such as the Jewish Federation.

- Shepherd's Center of the Northland Kansas City, Missouri

The Shepherd's Center of the Northland is a non-profit organization that provides support services for seniors, which includes transportation primarily to medical appointments. Limited transportation services are also provided for errands, grocery shopping, or other urgent requests. The program, which is run using volunteer operators, does not receive any direct governmental funding. Under current procedures, clients call the Shepherd's Center to schedule a trip giving at least a two-day notice. The Center, in turn, calls a volunteer and shares the logistics of the trip. The volunteer calls the client and verifies the arrangements. The use of volunteers in this way, which includes the use of the volunteers' personal vehicles, is cost-effective and has limited the operating expenses of the program. Another interesting aspect of this program is that passengers are not charged a fare; however, donations are accepted. Instead, the Shepherd's Center has been sustained in by successfully acquiring private grants and through an active fundraising agenda. 
- Independent Transportation Network Westbrook, Maine

ITN was established in 1995 through research funded by the Federal Transit Administration (FTA), the American Association of Retired Persons (AARP), and the Transportation Research Board (TRB). At no time has the program sought or received local government funding, and in 1996 ITN received a one-time in-kind $\$ 2,500$ grant from the state of Maine. Since 2001, the program has received no federal government funding and subsists entirely on membership dues, user fares, and voluntary community support.

Community support has come in the form of local healthcare providers, merchants, and businesses supplementing passenger fares; automobile donations; senior and adult child memberships; the annual "March of the Members" awareness campaign and fundraiser; and volunteer efforts.

\section{Use of Volunteers}

The organizations that utilize volunteers in the provision of senior transportation services attribute their success to the generosity and dedication of their volunteers. Recruiting and managing an effective volunteer corps is an everpresent challenge, and many programs have implemented strategies designed to support the efficient use of volunteers.

\section{Recruitment}

- Cecil County Department of Aging Transportation Program Elkton, Maryland

As previously discussed, the Cecil County Department of Aging's Transportation Program "Road Show" is a successful marketing tool for presenting the services that the agency offers to seniors. The Road Show program also serves as a means of recruiting volunteer drivers for the transportation program.

Once or twice each month the Cecil County Department of Aging presents the Road Show to churches, AARP groups, hospitals, and other gatherings attended 
by older adults. The Road Show is a traveling presentation during which supervisors from all divisions within the Department of Aging provide information as to what programs the agency sponsors and how seniors can avail themselves of the various services. The Road Show not only serves as a means of client outreach; it has proved to be a successful tool in volunteer driver recruitment for the organization.

- Partnership to Preserve Independent Living for Seniors and Persons with Disabilities-Transportation Reimbursement and Information Program (TRIP)

Riverside, California

TRIP has a different approach to volunteer driver recruitment as compared to any of the other programs that responded to the survey. Clients are typically coached to recruit their own volunteers among family, friends, neighbors, and others. TRIP staff report that this has been a successful means of securing volunteer drivers. Trips are not denied, and for those clients who are unable or unsuccessful in recruiting their own volunteers, TRIP will assist them in finding drivers among the program's established volunteer corps.

- The Shepherd's Center of Greater Kalamazoo Escort Transportation Program Kalamazoo, Michigan

Although several senior transportation programs utilize congregations as sources for volunteer recruitment as well as locating seniors who are in need of transportation services, the Shepherd's Center coordinates directly with someone representing a congregation. Program staff and the congregation coordinator designate a particular day, and several members of a particular congregation volunteer to be drivers on that day together as a group volunteer project. While this method is how the Shepherd's Center first began their transportation program, providing service one or two days per week, they have since expanded their program to include services Monday through Friday. The congregational designated volunteer day has been beneficial in developing the program's volunteer corps; however program staff report that they could benefit from approximately ten percent more volunteers.

Senior Transportation Alternatives: Why Are They Important and What Makes Them Work? 


\section{Screening/Training Process}

While most of the senior transportation programs reported there are minimum qualifications for volunteer drivers, such as valid licenses and automobile insurance, some organizations have implemented more stringent requirements. Several programs have enhanced their screening and training processes to ensure maximum safety for clients and drivers, as well as the overall well being of the organization.

- Del Mar Community Connections

Del Mar, California

Del Mar Community Connections is a nonprofit service organization operating within the city limits of Del Mar and some of the surrounding area. The service area population is approximately 4,600 persons. Community Connections provides door-to-door transportation and support services for seniors who are residents of Del Mar, temporarily or permanently disabled, or who are otherwise unable to drive themselves. The organization has one 9-13 passenger bus and 25 volunteer drivers that provide seniors with transportation to medical and shopping appointments.

To become a volunteer driver with Del Mar Community Connections, an applicant must have had no accidents during the previous year. In addition, volunteer applicants are required to attend an orientation and to participate in a course regarding the appropriate treatment of older and/or ill people.

- York County Community Action Corporation Sanford, Maine

Volunteer driver applicants to York County Community Action Corporation's senior transportation program are subjected to a variety of tests and training prior to being able to drive clients. Each applicant is personally interviewed, his or her motor vehicle and criminal records are evaluated, and references are thoroughly checked. Once approved, volunteers are required to attend a training session 
and may also participate in other training courses such as confidentiality, CPR, sign language, or mental illness.

\section{Scheduling of Volunteers}

Adequate scheduling of volunteers is a critical administrative function of any senior transportation services program that uses volunteer drivers. Because seniors are often being transported for medical appointments and other scheduled activities, timing is essential to customer satisfaction. Scheduling is also imperative for the coordination of trips and efficient driver time management. Transportation providers must balance client needs with volunteer driver availability. Although most organizations assert a constant need for more volunteers, they have determined effective strategies for scheduling volunteers, which also generally accommodate the demand for transportation.

- Call-A-Ride, Inc. Hebron, Indiana

Call-A-Ride, Inc. provides rides in accessible buses to seniors and the disabled in the Boone Township. Trip purposes include shopping, medical appointments, beauty shop appointments, or just about any other purpose. Call-A-Ride, Inc., which provides its services for free to passengers, is run completely by volunteers, including drivers, schedulers, officers, and Board of Directors. CallA-Ride, Inc. has 30 drivers, each of whom volunteers one full day (8am - 5pm) per month to drive the program's bus for transporting seniors in the area.

- Partnership to Preserve Independent Living for Seniors and Persons with Disabilities-Transportation Reimbursement and Information Program (TRIP)

Riverside, California

The TRIP program, previously noted for the recruitment practice of coaching clients to solicit their own volunteer drivers, does not actually schedule trips for clients and volunteers. Instead, rides are arranged directly between the client and his/her volunteer. This practice allows the senior and the driver to schedule 
appointments directly, thus providing service when and where the client needs it, at a mutually agreed upon time. Service is therefore available at any time on any day, depending upon the agreement reached by the volunteer driver and client, thereby fostering ultimate scheduling convenience for both. Furthermore, arrangements made directly between clients and volunteers eliminate the organization's responsibility for establishing a span of service, coordinating trips, maintaining a volunteer schedule, or similarly related scheduling matters.

Program staff report that this method of scheduling has proven to be of great benefit to TRIP, as well as to its clients and volunteers. This is attributed to the fact that travel occurs at a mutually agreed upon time, and that both participate in the negotiation of the terms and conditions. While TRIP counsels respect and consideration, within a short time a "friend" relationship often develops, resulting in a "high level of mutual involvement in the process and evolving concern for each other's needs and feelings." In fact, the responding program representative was able to recall two complaints within the past eight years regarding a "noshow."

\section{Use of Volunteer Vehicles}

Many senior transportation service programs utilize the personal vehicles of volunteers, and some do so exclusively. Because personal vehicles are used, accessibility is often limited to ambulatory persons; as such vehicles are not generally equipped to accommodate passengers with disabilities. While several organizations may offer mileage reimbursement to volunteer drivers, others provide no form of remuneration. In addition to decreasing the need for capital expenditures in acquiring vehicles, a number of programs contend that seniors prefer to ride in private automobiles as compared to vans or buses.

- Senior Connection Silver Spring, Maryland

The Senior Connection program does not maintain its own fleet. All vehicles used to provide the program's fare-free transportation services are owned, maintained, and operated by the organization's 60 part-time volunteer drivers. 
- York County Community Action Corporation (YCCAC) Sanford, Maine

For York County area residents who cannot be accommodated by the buses or vans in the YCCAC fleet due to mobility or scheduling constraints, the organization maintains more than 85 volunteer drivers who all use their personal vehicles to provide trips. If YCCAC vehicles and services can accommodate a client's needs, he/she does not qualify for volunteer transportation and would be referred to the appropriate YCCAC transportation program. Volunteers are reimbursed for mileage and tolls only. 
Senior Transportation Alternatives: Why Are They Important and What Makes Them Work?

Page 88 


\section{Chapter Five Summary and Recommendations}

The literature suggests and the focus groups confirmed that maintaining mobility is an important issue for seniors. Just like any other population segment, seniors fall on a wide spectrum as it relates to their views about driving. There are those who feel that it is their right to drive as long as they wish; while there are those who feel that there may be a point at which they should stop driving, whether they wish to continue or not. In another example, there are some seniors who believe that it is a senior's responsibility to self-regulate and make determinations regarding his or her ability to drive. On the other hand, there are seniors who believe that federal, state, or local government should have a more significant role in such decisions. With regard to testing and licensure, some seniors believe that they should not be held to standards any different than the rest of the population; while some believe that more stringent standards, such as additional vision testing, are called for.

Regardless of where seniors may fall on the spectrum, the results of this report suggest that most of them agree that it is extremely important for transportation alternatives to be provided for seniors. This report does not attempt to relate to a particular end of the spectrum. Instead, it addresses the importance of transportation alternatives for seniors, which was a common theme among all of the focus group discussions.

The primary concern of seniors is that when they reach the point where they are no longer able to drive, by either their own decision or as a result of some other determination, their quality of life can be greatly diminished due to the lack of transportation options. Such a realization awakens a variety of emotions, including fear, anger, and depression. Much of the literature on the subject of driving reduction and cessation by seniors suggests that there is an associated link between a senior's quality of life and his or her ability to get around. This suggestion was vehemently confirmed by most of the focus group participants. Some of them acknowledged fearing the day when they would no longer be able to drive and most specifically attributed that fear to not being able to shop, visit family and friends, or make doctor's appointments rather than missing the act of driving.

Senior Transportation Alternatives: Why Are They Important and What Makes Them Work? 
The participants in the focus groups made reference to the difficulties they face regarding accessing alternative transportation. The obstacles included:

- Unfamiliarity with transportation alternatives in their community

- Fixed-route transit bus stops too far from origin and/or destination

- Do not know how to catch a fixed-route transit bus

- Do not feel safe on fixed-route transit bus

- Physical limitations pose difficulty in boarding and alighting a transit bus

- Do not like to ask family or friends for a ride

- Taxi service is expensive

- Fixed-route transit scheduling is inconvenient

Many said that they were not familiar with transportation alternatives in their communities. Others said that some alternatives, such as transit buses, are difficult to access because of the distance to the bus stops. Although the communities in which the focus groups were held each had a paratransit system, very few of the focus group participants were familiar with such programs.

The seniors cited many of the same reasons for not utilizing fixed-route transit that other segments of the population express. Some of the focus group participants claimed that a fixed-route system that was more convenient and with closer bus stops might be more attractive to them as a viable transportation alternative. Otherwise, it was the least appealing alternative among focus group participants.

One of the four focus group discussions was held at a senior center that had its own alternative transportation system for it clients. These focus group participants were able to speak to the attributes of such an alternative. They were very pleased with the program and were able to compare their quality of life before and after they began using the service. The participants spoke of the many reasons why they thought the service was so well-liked by the members at their senior center. They included:

- The drivers care and treat the seniors with respect

- The service is frequent and reliable

Senior Transportation Alternatives: Why Are They Important and What Makes Them Work? 
- Passengers can make new friends, but are usually familiar or comfortable with who is on the bus or van

Interestingly, all but one of the participants in this particular focus group were non-drivers; however, some said that they could drive if they wanted to but do not feel that they needed to as a result of the service provided by the senior center. On the other hand, the seniors from the other discussion groups were far less optimistic about their alternatives when they decide to give up driving. Most still drive and do not look forward to the prospect of not driving because of the uncertainty surrounding their alternatives.

The results of the written survey to senior transportation providers, as discussed in Chapter Three, suggest that most providers are aware of the concerns that today's seniors have regarding their independence and mobility. Some programs have made concentrated efforts to focus on outreach and marketing to address the concern that seniors have about not being familiar with their transportation options. Yet still, other programs have gone beyond allowing transportation for medical appointments only to include all trip purposes. One respondent wrote, "Clients go to beauty shops, shopping, banks, post office, medical appointments, visiting relatives, the food pantry, drugstores, grocery stores, and out to lunch."

Based on the results of the survey, it is also clear that many providers are concerned about making the provision of services affordable. Over half of the responding providers do not charge their clients a fee. Nearly a quarter of the providers accept donations. Based on survey responses and follow-up interview discussions, most of the sponsoring organizations feel that the provision of transportation alternatives for seniors is a worthy activity and should be kept affordable through use of public and private grants and the use of volunteer operators.

\section{Recommendations}

The focus group discussions, as well as the survey results, confirmed that there are senior transportation providers that are in touch with the concerns and perceptions of seniors. Many of the strategies employed by these providers can 
be duplicated or mirrored by other communities in search of ways to better serve the transportation needs of their senior populations. The following are recommendations resulting from the focus group discussions and survey result analyses.

- Make client outreach and marketing efforts a priority

Many of the participants in the focus group discussions were not aware of the transportation alternatives available to them in their respective areas. For many communities, the paratransit service providers are overwhelmed by the number of clients that they have and this is further complicated by lack of funding. As a result, providers do not always look forward to recruiting additional clients; however, by limiting or eliminating outreach, many seniors are unfamiliar with alternatives and risk isolation. Client outreach and marketing efforts can also include shifting clients who are physically able to fixed-route services if they are available, convenient, and accessible.

- Partner with other senior support providers to produce a combined resource of information

Some of the successful senior transportation providers are part of a much broader organization or entity that provides overall support for seniors. This support includes a variety of services, such as meals, counseling, social activities, medical referrals, and transportation. One complaint of the participants in the focus groups was that there is not usually a central place where seniors can learn of all opportunities. Several seniors suggested that a pamphlet or brochure that describes all of the services available to older persons in the community be prepared and distributed to locations that seniors frequent. Several of the senior transportation providers who responded to the survey acknowledged cooperating with other agencies and senior support services providers to produce a "one-stop shopping" type of information source. 


\section{- Utilize volunteers in creative ways}

Some communities, as a result of either lack of funds or preference in operational structure, provide senior transportation services primarily through the use of volunteers. In some cases, volunteers are operators, schedulers, and even facilitate the administration of the senior transportation programs. Some of the communities that participated in the survey and follow-up interview process acknowledged relying heavily on the contributions of volunteers. They suggested that they have employed volunteer recruitment efforts through independent organizations, such as churches and community service groups. At least one of the programs that responded to the survey allows volunteers to play an direct role in scheduling so that trips are convenient for the volunteer as well as the client.

Several of the contacts from programs interviewed during the follow-up process recommended that if communities are attempting to organize a volunteer-based system, it is important to implement steps to ensure that the volunteers do not experience "burn out." An example used by one provider was the recruitment of enough volunteers so that one never serves more than one day per month.

- Establish travel training programs designed to assist seniors with using fixed-route transit

In response to the concerns some seniors have regarding how to travel by transit bus, many transit agencies have coordinated with other entities for travel training, and others have developed in-house training programs. Trainers, volunteers, or transit agency staff instruct patrons in such tasks as how to read and use transit maps and schedules, how to plan a trip, boarding and alighting the bus, making transfers, situational problem-solving, using mobility devices such as wheelchair lifts, and bus safety and security. Travel training has been used successfully by transit agencies in creating a stronger base of passengers from the senior population. Eliminating the psychological barrier of uncertainty related to bus transit often exposes a transportation option that previously was enigmatic or perhaps not even considered as an alternative to driving. 
- Evaluate the location of fixed-route bus stops in senior-dominated communities

Many older adults experience difficulty in walking or maneuvering within those areas served by fixed-route transit. Of particular concern are the distances between bus stops and points of origin/destination. The standard urban transit walking distance of one-quarter mile may pose an obstacle or even impossibility for senior citizens with restricted mobility or respiratory difficulties. Fixed-route bus stops in areas with high senior population densities deserve periodic evaluation, in consultation with the senior community, to determine the appropriateness of stop locations and distances.

- Improve or modify the transit stop environment to encourage the use of public transportation by senior citizens

Related to seniors' concerns regarding the location of bus transit stops are the surrounding environment and amenities of a bus stop. Transit environments must accommodate a variety of mobility assistance devices such as wheelchairs, scooters, and walkers. While ADA regulations govern the design of the stop itself, access to and from the stop is often what creates hazards and inaccessibility for older adults. A lack of crosswalks, crossing signals, and sidewalks, or the presence of uneven or slippery terrain poses safety risks to seniors attempting to navigate to and/or from the stop. Seniors also appreciate shelters, or at least the placement of a bench at the stop to serve as a resting place while awaiting the arrival of the bus. Although older people tend to limit their nighttime travel, bus stops should be well lit for safety and security purposes.

- Make driver assessment tools available at community and senior centers

Many of the focus group participants described themselves as self-governing and acknowledged that they have recognized that their ability has diminished somewhat as they have aged. In response, some no longer drive at night and others limit the distances traveled. In addition, several of the participants completed the AARP Driver Safety Program. By making driver assessment tools available at community and senior centers, as well as at medical establishments,

Senior Transportation Alternatives: Why Are They Important and What Makes Them Work? 
communities can provide their senior populations an avenue by which they may identify their driving deficiencies. Whether those deficiencies result in the reduction or cessation of driving, or if they encourage the seniors to modify their driving practices in other ways, driver assessment tools should be a common resource in communities across the country.

- Maximize outreach opportunities to ethnic minority groups

The populations of ethnic minority groups within the United States are rapidly increasing. Aging members of Hispanic, African American, Asian, American Indian, and other minority communities are in need of transportation services, generating additional opportunities for alternative transportation programs to serve these populations. Furthermore, expanding the range of clients will enhance the opportunities that programs have to partner with new and different community organizations, and to increase the volunteer base for those agencies that make use of volunteers.

The analysis of local demographic information can assist senior transportation programs in determining the need for outreach to minority communities, and assessing the potential for new partnerships. Such information may also aid program staff in evaluating the usefulness of cultural awareness training, and whether volunteers or staff with non-English language skills might be beneficial to the organization and its clients.

\section{- Consider weather conditions in determining types of services}

Senior transportation providers that operate in geographic areas with extreme weather conditions must take weather patterns and client mobility levels into consideration when deciding to offer specialized transportation services. Snow, ice, rainstorms, and extreme heat or cold can affect seniors' ability to navigate safely, particularly if they experience limited mobility. Many successful programs operating in such areas offer their clients door-to-door services, often providing assistance in navigating steps, sidewalks, and driveways. 
- Perform regular needs assessments and client satisfaction evaluations

Needs assessments and satisfaction evaluations allow senior transportation providers to evaluate whether they are meeting the needs of clients and potential clients, as well as the level of satisfaction with the organization's existing services. As with any other population segment, seniors are more likely to continue using a service in which they are satisfied. In addition, they are more likely to share their experiences with others if it is a service that is successfully meeting their needs. Some of the more successful senior transportation programs are in touch with the needs of their clients through consistent feedback and genuine attempts to adjust to those needs and evaluations.

\section{- Increase financial support for senior transportation programs}

It is imperative that state and federal funding programs designed to strengthen senior support programs, such as transportation, are continued and increased to levels that will ensure that programs on the local levels are sustained. Hundreds of senior transportation programs in the United States are operating with minimal funding. These programs provide an invaluable service to our communities and deserve to be favorably considered when distributing resources. 


\section{Afterword}

In 2003, several tragedies involving senior drivers were highlighted in the media. It spurred conversation on radio talk shows and cable news programs between many interested parties. Florida's legislature, as with many other states, was considering amending its license renewal requirements prior to the most recent tragedies.

Florida currently has no separate license renewal requirements for elderly drivers. However, beginning in 2004, the State of Florida will require any driver who is age 79 or older to submit to a vision test at a Department of Motor Vehicles office when renewing their license. For those persons renewing by mail, they may have their vision tested by a licensed physician or optometrist; after which, the medical professional must send the results to the licensing agency. Currently, Florida allows drivers, regardless of age, to renew their licenses by mail or via the internet for up to two successive renewals. Licenses are issued for six years if the person has maintained a clean driver's license. Otherwise, a license is renewed for a four-year period. Information on the licensing requirements for other states is available at the website for the Insurance Institute for Highway Safety (http://www.hwysafety.org/safety facts/state laws/older drivers. htm).

Regulatory efforts to minimize the number of senior drivers on the road are a bandage solution. Taking away someone's license does not address the much bigger issue of the provision of alternatives for the purpose of maintaining mobility in the later years of life. Researchers, practitioners, and seniors alike believe that elderly drivers do not acknowledge or are not aware of alternatives to driving their automobiles. Convenient and dignified transportation alternatives provide seniors an attractive option for maintaining their mobility and independence. Ultimately, such alternatives may prevent some seniors who can no longer safely operate a vehicle from making a potentially tragic decision. 
Senior Transportation Alternatives: Why Are They Important and What Makes Them Work?

Page 98 


\section{Bibliography}

American Public Transportation Association (2002). The Benefits of Public Transportation: Mobility for the Aging Population. Accessed in April 2003 at http://www.apta.com/research/info/online/documents/seniors.pdf.

Beverly Foundation. (2001). Supplemental Transportation Programs for Seniors. Prepared for AAA Foundation for Traffic Safety.

Bruff, J. Thomas and Jennifer Evans. (1999). Elderly Mobility and Safety -The Michigan Approach: Final Plan of Action. Prepared by Southeast Michigan Council of Governments for the Michigan State Safety Commission.

Burkhardt, Jon E. (1998). Safe mobility for life. Community Transportation. Volume 16, Number 7: 20-22,37.

Burkhardt, Jon E. (1999). Mobility Changes: Their Nature, Effects, and Meaning for Elders Who Reduce or Cease Driving. Transportation Research Record. Number 1671:11-18.

Charlton, Judith, Brian Fildes, Magda Les, and Jennie Oxley. (2001). Selfregulatory behaviour of older drivers. Proceedings of the Road Safety Research, Policing, and Education Conference. Melbourne, Australia, Vol. 1: 47-55.

Clark, Catherine. (1999). Senior Drivers. Report aired on CBC News on November 21, 2000. Reproduction accessed at www.cbc.ca/consumers/market/files/cars/seniordrivers/.

Coughlin, Dr. Joseph F. and Annalynn Lacombe. (1997). Transportation and our aging population: Volpe Center helps shape future policy. Volpe Journal. Spring 1997:41-47.

Dellinger, Ann M., Jean A. Langlois, and Guohua Li. (2002). Fatal crashes among older drivers: Decomposition of rates into contributing factors. American Journal of Epidemiology. Volume 155, Number 3: 234-241. 
Eby, David W., Deborah A. Trombley, Lisa J. Molnar, and Jean T. Shope. (1998). The Assessment of Older Drivers' Capabilities: A Review of the Literature. University of Michigan Transportation Research Institute.

Glasgow, Nina. (2002). Older Americans' patterns of driving and using other transportation. Rural America. Volume 15, Number 3: 26-31.

Hetzel, Lisa and Annetta Smith. (2001). The 65 Years and Over Population: Census 2000 Brief. U.S. Department of Commerce.

Insurance Institute for Highway Safety. (2001). Older Drivers Up Close: They Aren't Dangerous Except Maybe to Themselves. Status Report. Volume 36, Number 8: pp.1-8.

Kostyniuk, Lidia P., Deborah A. Trombley, and Jean T. Shope. (1998). The Process of Reduction and Cessation of Driving Among Older Drivers: A Review of the Literature. The University of Michigan Transportation Research Institute. UMTRI-98-23.

Kostyniuk, Lidia P. and Jean T. Shope. (1998). Reduction and Cessation of Driving Among Older Drivers: Focus Groups. The University of Michigan Transportation Research Institute. UMTRI-98-26.

L.A. Metro Multi-Disciplinary Team. Dangerous Driving and Seniors. Accessed at www.LA4Seniors.com on April 17, 2002.

Maricopa Association of Governments. (2001). Regional Action Plan on Aging and Mobility.

Morris, Jim. (1999). Should Elderly Drivers Be Tested? In cooperation with correspondent Siobhan Darrow and the Associated Press. Accessed on July 22, 2002 at www.cnn.co/US/9906/28/dangerous.drivers/.

National Center for Statistics and Analysis. (2001). Traffic Safety Facts 2001: Older Population. U.S. Department of Transportation, National Highway Traffic Safety Administration. 
Owsley, Cynthia, Karlene Ball, Gerald McGwin, Michael E. Sloane, Daniel L. Roenker, Milton F. White, and E. Todd Overly. (1998). Visual processing impairment of risk of motor vehicle crashes among older drivers. Journal of the American Medical Association. Volume 278: 1083-1088.

Persson, Diane. (1993). The Elderly Drivers: Deciding when to stop. The Gerontologist. Volume 33, Number 1: 88-91.

Schneider, Jeffrey James. (2002). Useful Field of View as an Indicator of Accident Risk: Results from a College Sample.

Service Nova Scotia and Municipal Relations. (2001). Senior Drivers Get Discount on Safe Driving Course. Accessed on Nova Scotia, Canada's official website at http://www.gov.ns.ca/news/details.asp?id=20010927012 on April 12, 2003.

Skinner, David and Mary D. Stearns. (1999). Safe Mobility in An Aging World. John A. Volpe National Transportation Systems Center.

Staplin, Loren, Kathy H. Lococo, Joseph Stewart, and Lawrence E. Decina. (1999). Safe Mobility for Older People Notebook. National Highway Traffic Safety Administration, DOT HS 808853.

Straight, Audrey. (1997). Community Transportation Survey. American Association of Retired Persons.

Straight, Audrey and Ann McCarty Jackson. (1999). Older Drivers. Public Policy Institute of the American Association of Retired Persons.

Traffic Safety Center. (2002). How Older Adults Will Drive Transportation Policy. Traffic Safety Center Online Newsletter. Volume 1, Number 1: August 2002. Accessed at http://www.tsc.berkeley.edu/newsletter/aug02/frontpage.html 
USAA Educational Foundation. (2002). Driving Safely While Aging Gracefully. Brochure developed in cooperation with the American Association of Retired Persons and the National Highway Traffic Safety Administration. Also may be accessed at www.usaaedfoundation.org/auto/autoSafety/as03/as03.htm.

U.S. Department of Health and Human Services. (2002). A Profile of Older Americans: 2002.

U.S. Department of Transportation. (1999). Improving Transportation for a Maturing Society. DOT-P10-97-01.

Wilkins, Jean W., Jane C. Stutts, and Sally J. Schatz. (1999). Premature Reduction and Cessation of Driving: Preliminary Study of Women who Choose Not to Drive or To Drive Infrequently. Transportation Research Record. Number 1693: 86-90. 